This document is confidential and is proprietary to the American Chemical Society and its authors. Do not copy or disclose without written permission. If you have received this item in error, notify the sender and delete all copies.

\title{
Synthesis and Structure of Trinuclear W3S4 Clusters Bearing Aminophosphine Ligands and their Reactivity towards Halides and Pseudohalides
}

\begin{tabular}{|r|l|}
\hline Journal: & Inorganic Chemistry \\
\hline Manuscript ID: & ic-2014-025313.R1 \\
\hline Manuscript Type: & Article \\
\hline Date Submitted by the Author: & n/a \\
\hline Complete List of Authors: & $\begin{array}{l}\text { Beltran, Tomas; Universitat Jaume I, Química Física i Analítica } \\
\text { Pino-Chamorro, Jose Angel; Universidad de Cadiz, Ciencia de los Materiales } \\
\text { e Ingenieria Metalurgica y Quimica Inorganica } \\
\text { Fernández-Trujillo, M. Jesús; Universidad de Cadiz, Ciencia de los } \\
\text { Materiales e Ingenieria Metalurgica y Quimica Inorganica } \\
\text { Safont, Vicent; Universidad Jaume I, Quimica Física i Analítica } \\
\text { Basallote, Manuel; Universidad de Cadiz, Ciencia de los Materiales e Ing. } \\
\text { Met. y Quimica InorgÃ?Âinica } \\
\text { Llusar, Rosa; Universitat Jaume I, Química Física i Analítica }\end{array}$ \\
\hline
\end{tabular}




\title{
Synthesis and Structure of Trinuclear $\mathrm{W}_{3} \mathrm{~S}_{4}$ Clusters
}

\section{Bearing Aminophosphine Ligands and their Reactivity}

\section{towards Halides and Pseudohalides}

\author{
Tomás F. Beltrán, ${ }^{a, ~}{ }^{\prime} J o s e$ Ángel Pino-Chamorro, ${ }^{b, ~}{ }^{*}$ M. Jesús Fernández-Trujillo, ${ }^{b}$ Vicent S. Safont, \\ ${ }^{*}$ a Manuel G. Basallote, *b and Rosa Llusar *a
}

This work is dedicated to the memory of Prof. Zvi Dori

a Departament de Química Física i Analítica, Universitat Jaume I, Av. Sos Baynat s/n, 12071 Castelló, Spain.

b Departamento de Ciencia de los Materiales e Ingeniería Metalúrgica y Química Inorgánica, Facultad de Ciencias, Universidad de Cádiz, Apartado 40, Puerto Real, 11510 Cádiz, Spain.

${ }^{*}$ These authors contributed equally to this work.

* authors for correspondence: sixte.safont@qfa.uji.es, manuel.basallote@uca.es, rosa.llusar@uji.es 


\begin{abstract}
The aminophosphine ligand (2-aminoethyl)diphenylphosphine (edpp) has been coordinated to the $\mathrm{W}_{3}\left(\mu_{3}-\mathrm{S}\right)(\mu-\mathrm{S})_{3}$ cluster unit to afford the trimetallic $\left[\mathrm{W}_{3} \mathrm{~S}_{4} \mathrm{Br}_{3}(\mathrm{edpp})_{3}\right]^{+}\left(\mathbf{1}^{+}\right)$complex in one step synthesis and high yields. Related $\left[\mathrm{W}_{3} \mathrm{~S}_{4} \mathrm{X}_{3}(\mathrm{edpp})_{3}\right]^{+}$clusters $\left(\mathrm{X}=\mathrm{F}^{-}, \mathrm{Cl}^{-}, \mathrm{NCS}^{-}, \mathbf{2}^{+}-\mathbf{4}^{+}\right)$have been isolated by treating $\mathbf{1}^{+}$with the corresponding halide or pseudohalide salts. The structure of complexes $\mathbf{1}^{+}$to $\mathbf{4}^{+}$contains a $\mathrm{W}_{3} \mathrm{~S}_{4}$ incomplete cubane-type cluster unit, and only one of the possible isomers is formed, the one with the phosphorous atoms trans to the capping sulphur and the amino groups trans to the bridging sulphurs. The remaining coordination position on each metal is occupied by $\mathrm{X}^{-}$. Detailed studies using stopped-flow, ${ }^{31} \mathrm{P}\left\{{ }^{1} \mathrm{H}\right\} \mathrm{NMR}$, and ESI-MS have been carried out in order to understand the solution behaviour and the kinetics of inter-conversion between the $\mathbf{1}^{+}$, $\mathbf{2}^{+}, \mathbf{3}^{+}$and $\mathbf{4}^{+}$species in solution. DFT calculations have been also carried out on the reactions of cluster $\mathbf{1}^{+}$with the different anions. The whole set of experimental and theoretical data indicate that the actual mechanism of substitutions in these clusters is strongly dependent on the nature of the leaving and entering anions. The interaction between an entering $\mathrm{F}^{-}$and the amino group coordinated to the adjacent metal have been also found to be especially relevant in the kinetics of these reactions.
\end{abstract}




\section{Introduction}

Multifunctional catalysis in which metal-metal and metal-ligand interactions cooperate to chemically transform a substrate, as natural enzymes do, is a field of central interest nowadays. ${ }^{1}$ In this context, cuboidal $\mathrm{M}_{3} \mathrm{~S}_{4}(\mathrm{M}=\mathrm{Mo}, \mathrm{W})$ cluster chalcogenides, represented in Figure 1, and their closely related heterobimetallic $\mathrm{M}_{3} \mathrm{M}^{\prime} \mathrm{S}_{4}\left(\mathrm{M}^{\prime}=\right.$ transition metal) complexes, have been extensively investigated. ${ }^{2}$ In general molybdenum and tungsten $\mathrm{M}_{3} \mathrm{~S}_{4}$ clusters are electron precise with six electrons for the formation of three metal-metal bonds and a formal oxidation state of +4 for the metals, Mo or W.
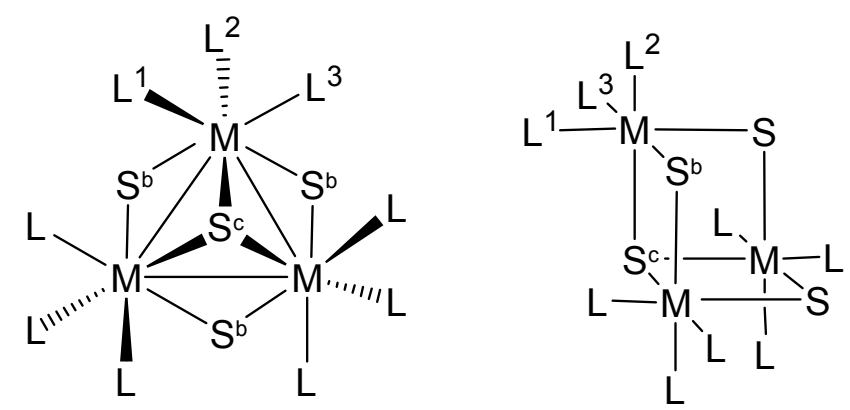

Figure 1. Two alternative views of the cuboidal $\mathrm{M}_{3} \mathrm{~S}_{4} \mathrm{~L}_{9}$ cluster, showing the capping $\left(\mathrm{S}^{\mathrm{c}}\right)$ and bridging $\left(\mathrm{S}^{\mathrm{b}}\right)$ sulfur atoms. M-M bonds are omitted for clarity in the right side figure.

Particular attention has been placed in our groups to their diphosphino $\left.\left[\mathrm{M}_{3} \mathrm{~S}_{4} \mathrm{X}_{3} \text { (diphosphine }\right)_{3}\right]^{+}(\mathrm{X}=$ halide, hydride $)$ derivatives, because of the major role that transition metal complexes containing phosphines play in homogeneous catalysis. ${ }^{3-11}$ The coordination mode of the diphosphine ligands in these complexes affords a single isomer, represented in Figure 2, with one phosphorous atom trans to the capping sulfur $\left(\mathrm{S}^{\mathrm{c}}\right)$ and one trans to the bridging sulfur $\left(\mathrm{S}^{\mathrm{b}}\right)$ resulting in quiral clusters with $\mathrm{C}_{3}$ symmetry. All three metals share an identical coordination environment. In the last years, aminophosphines have emerged as versatile ligands because they combine the $\pi$-acceptor character of the phosphorous atom with the $\sigma$-donor properties of nitrogen. ${ }^{12-14}$ In addition, the NH moieties from the aminophosphine directly coordinated to the metal centre, can take part in the catalytic reaction by cooperation with the metal-bonded species. ${ }^{1} \mathrm{~A}$ 
priori several isomeric forms are feasible upon coordination of a bifunctional ligand, such as aminophosphine, to the $\mathrm{Mo}_{3} \mathrm{~S}_{4}$ unit assuming an analogous coordination to that of diphosphines as illustrated in Figure 2.
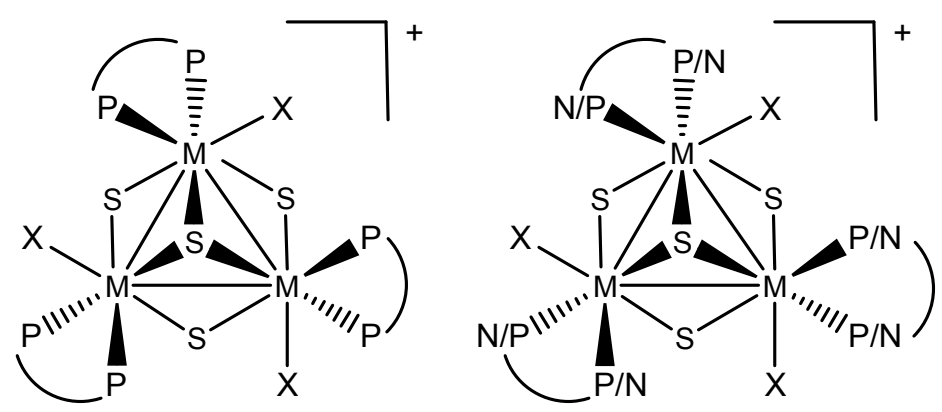

Figure 2. Structure of one of the two enantiomeric forms of $\left[\mathrm{M}_{3} \mathrm{~S}_{4} \mathrm{X}_{3}(\text { diphosphine })_{3}\right]^{+}$(left) and proposed isomeric structures for $\left[\mathrm{M}_{3} \mathrm{~S}_{4} \mathrm{X}_{3}(\text { aminophosphine })_{3}\right]^{+}$(right)

To promote further development in the field of catalysis, it is essential to understand the substitution reaction mechanisms as well as to gather a detailed knowledge on the substrate-binding activation. For example, mechanistic studies on the proton transfer reaction between trinuclear diphosphino $\mathrm{M}_{3} \mathrm{~S}_{4}(\mathrm{M}=\mathrm{Mo}, \mathrm{W})$ cluster hydrides and acids support the formation of dihydrogenbonded adducts by acid attack to the hydrides in the $\mathrm{X}$ sites of Figure 2 as intermediates or transition states. ${ }^{4,15-17}$ This finding led us to investigate the catalytic reduction of organic substrates mediated by these trimetallic hydrides. In collaboration with Beller`s group, we found that trinuclear $\mathrm{Mo}_{3} \mathrm{~S}_{4}$ hydrides functionalized with outer diphosphane ligands are excellent catalysts for the highly selective reduction of nitroarenes to the corresponding anilines. ${ }^{9}$ Tungsten and molybdenum $\mathrm{M}_{3} \mathrm{~S}_{4}$ hydrides bearing diphosphines are also active catalysts in the selective hydrodefluorination of pentafluoropyridine in the para position, using silanes as hydrogen sources. ${ }^{6}$ Motivated by the good catalytic performance of group eight and nine aminophosphino complexes in hydrogenation and transfer hydrogenation reactions, we decided to design synthetic procedures aimed to functionalize the highly robust $\mathrm{W}_{3} \mathrm{~S}_{4}$ cluster core moiety with aminophosphine ligands. ${ }^{1,18-26}$ In particular, we have 
chosen (2-aminoethyl)diphenylphosphine (edpp), bearing a $\mathrm{NH}_{2}$ function that can serve not only as coordination group but also as hydrogen donor or acceptor. This versatility is especially relevant in the field of multifunctional or self-assembled catalysis.

The use of rational synthetic procedures for the preparation of trinuclear metal chalcogenides has contributed enormously to the development of the chemistry of transition metal clusters. Polymeric $\left\{\mathrm{M}_{3} \mathrm{Q}_{7} \mathrm{X}_{4 / 2} \mathrm{X}_{2}\right\}_{\mathrm{n}}$ one-dimensional phases are the preferred starting material to entry the chemistry of incomplete cubane-type $\mathrm{M}_{3} \mathrm{Q}_{4}$ clusters containing bidentated phosphines, i.e. dmpe (1,2-bis(dimethylphosphino)ethane) or dppe (1,2-bis(diphenylphosphino)ethane), as well as optically pure chiral diphosphines such as Me-BPE (1,2-bis[2,5-(dimethylphospholan-1-yl)] ethane). ${ }^{5,27,28}$ In the last case the synthesis came out to be enantioselective to afford optically pure cluster complexes in almost quantitative yields.

Herein, we present the coordination of edpp to the $\mathrm{W}_{3} \mathrm{~S}_{4}$ cluster unit to afford complexes of formula $\left[\mathrm{W}_{3} \mathrm{~S}_{4} \mathrm{X}_{3}(\mathrm{edpp})_{3}\right]^{+}(\mathrm{X}=\mathrm{F}, \mathrm{Cl}, \mathrm{Br}, \mathrm{NCS})$, closely related to the $\left.\left[\mathrm{M}_{3} \mathrm{~S}_{4} \mathrm{X}_{3} \text { (diphosphine }\right)_{3}\right]^{+}(\mathrm{M}=$ Mo, W) compounds widely investigated in our groups. ${ }^{5,8,29,30}$ At this point, it is important to note that the kinetics and mechanism of substitution reactions in $\mathrm{M}_{3} \mathrm{Q}_{4}$ clusters have not been studied in detail, except for the case of the aqua clusters, which were comprehensively studied by the group of Sykes. ${ }^{31-35}$ During the course of the synthetic work with the $\left[\mathrm{W}_{3} \mathrm{~S}_{4} \mathrm{X}_{3}(\mathrm{edpp})_{3}\right]^{+}$clusters it was observed that $\mathrm{X}$ ligands are easily substituted in acetonitrile solution and this prompted us to carry out a kinetico-mechanistic study of these reactions combining kinetic experiments and DFT calculations. The results obtained are reported in this paper and reveal a very rich mechanistic behavior.

\section{Experimental Section}

\section{General Remarks.}

Elemental analyses were carried out on a EuroEA3000 Eurovector Analyser. Electrospray mass spectra were recorded with a Quattro LC (quadrupole-hexapole-quadrupole) mass spectrometer with 
an orthogonal Z-spray electrospray interface (Micromass, Manchester, UK). The cone voltage was set at $20 \mathrm{~V}$ unless otherwise stated using $\mathrm{CH}_{3} \mathrm{CN}$ as the mobile phase solvent. Sample solutions have been infused via syringe pump directly connected to the ESI source at a flow rate of $10 \mu \mathrm{L} / \mathrm{min}$ and a capillary voltage of $3.5 \mathrm{kV}$ was used in the positive scan mode. Nitrogen was employed as drying and nebulising gas. Isotope experimental patterns were compared with theoretical patterns obtained using the MassLynx 4.0 program. ${ }^{36}{ }^{19} \mathrm{~F}\left\{{ }^{1} \mathrm{H}\right\}$ and ${ }^{31} \mathrm{P}\left\{{ }^{1} \mathrm{H}\right\}$ NMR spectra were recorded on a Varian Innova $300 \mathrm{MHz}$ and $500 \mathrm{MHz}$, using $\mathrm{CD}_{3} \mathrm{CN}$ as solvents and referenced to $\mathrm{CFCl}_{3}$ and $85 \% \mathrm{H}_{3} \mathrm{PO}_{4}$, respectively.

\section{Synthesis}

All reactions were carried out under a nitrogen atmosphere using standard Schlenck techniques. The solid polymeric $\left\{\mathrm{W}_{3} \mathrm{~S}_{7} \mathrm{Br}_{4}\right\}_{\mathrm{n}}$ phase was obtained according to literature methods. ${ }^{37}$ Solvents were dried and degassed by standard methods before use. Edpp ligand was obtained from Strem Chemicals and used without further purification.

$\left[\mathbf{W}_{3} \mathbf{S}_{4} \mathbf{B r}_{3}(\mathbf{e d p p})_{3}\right] \mathbf{B r}(\mathbf{1}(\mathbf{B r}))$ To a suspension of $\left\{\mathrm{W}_{3} \mathrm{~S}_{7} \mathrm{Br}_{4}\right\}_{\mathrm{n}}(0.200 \mathrm{~g}, 0.183 \mathrm{mmol})$ in $\mathrm{CH}_{3} \mathrm{CN}(80$ $\mathrm{mL})$ was sequentially added $\mathrm{HBr} 0.5 \mathrm{M}\left(\right.$ in $\left.^{\mathrm{CH}_{3} \mathrm{CN}}\right)(1.3 \mathrm{~mL} 0.650 \mathrm{mmol})$ and edpp $(0.275 \mathrm{~g}, 1.20$ mmol) under nitrogen and the reaction mixture was refluxed for $48 \mathrm{~h}$. The reaction occurs with a color change from brown to blue. After the mixture was cooled to r.t., the suspension was filtrated, the green solution was concentrated under reduced pressure until one fourth of its initial volume and $50 \mathrm{~mL}$ of ethanol were added. Then the desired product was precipitated with diethyl ether. Finally, the blue solid was separated by filtration and washed with ethanol: diethyl ether (1:10) to yield 0.190 g (62\% yield) of an air stable product characterized as $\mathbf{1}(\mathrm{Br}) .{ }^{31} \mathrm{P}\left\{{ }^{1} \mathrm{H}\right\} \mathrm{NMR}\left(\mathrm{CD}_{3} \mathrm{CN}, 121 \mathrm{MHz}\right)$ $\delta=15.2\left(3 \mathrm{P}, \mathrm{s},{ }^{1} \mathrm{~J}_{\mathrm{P}-\mathrm{W}}=93.7 \mathrm{~Hz}\right)$. ESI-MS $\left(\mathrm{CH}_{3} \mathrm{CN}, 20 \mathrm{~V}\right) \mathrm{m} / \mathrm{z}: 1607.9\left[\mathrm{M}^{+}\right]$. Anal. Calc. $\mathrm{W}_{3} \mathrm{Br}_{4} \mathrm{~S}_{4} \mathrm{~N}_{3} \mathrm{P}_{3} \mathrm{C}_{42} \mathrm{H}_{48}:$ C, 29.9; H, 2.9; N, 2.5. Found: C, 30.2; H, 3.1; N, $2.7 \%$.

$\left[\mathbf{W}_{3} \mathbf{S}_{4} \mathbf{C l}_{3}(\mathbf{e d p p})_{3}\right] \mathbf{B r}(\mathbf{2}(\mathbf{B r}))$ To a dark blue solution of $\mathbf{1}(\mathrm{Br})(0.050 \mathrm{~g}, 0.030 \mathrm{mmol})$ in $\mathrm{CH}_{3} \mathrm{CN}(25$ $\mathrm{mL})$ was added $\mathrm{Pr}_{4} \mathrm{NCl}(0.044 \mathrm{~g}, 0.200 \mathrm{mmol})$ under nitrogen and the reaction mixture was stirred 
for $1 \mathrm{~h}$ at r.t. The reaction occurs with a slight color change from blue to violet. The solution was concentrated under reduced pressure and the desired product was precipitated by adding diethyl ether. Finally, the blue solid was separated by filtration, washed with water, diethyl ether and dried under vacuum to yield $0.038 \mathrm{~g}$ (82\% yield) of an air stable product characterized as $2(\mathrm{Br}) .{ }^{31} \mathrm{P}\left\{{ }^{1} \mathrm{H}\right\}$ NMR $\left(\mathrm{CD}_{3} \mathrm{CN}, 121 \mathrm{MHz}\right) \delta=18.1\left(3 \mathrm{P}, \mathrm{s},{ }^{1} \mathrm{~J}_{\mathrm{P}-\mathrm{W}}=92.5 \mathrm{~Hz}\right)$. ESI-MS $\left(\mathrm{CH}_{3} \mathrm{CN}, 20 \mathrm{~V}\right) \mathrm{m} / \mathrm{z}: 1474.0$ $\left[\mathrm{M}^{+}\right]$. Anal. Calc. $\mathrm{W}_{3} \mathrm{Cl}_{3} \mathrm{BrS}_{4} \mathrm{~N}_{3} \mathrm{P}_{3} \mathrm{C}_{42} \mathrm{H}_{48}: \mathrm{C}, 32.5 ; \mathrm{H}, 3.1 ; \mathrm{N}, 2.7$. Found: $\mathrm{C}, 32.8 ; \mathrm{H}, 3.2 ; \mathrm{N}, 3.0 \%$.

$\left[\mathbf{W}_{3} \mathbf{S}_{4} \mathbf{F}_{3}(\mathbf{e d p p})_{3}\right] \mathbf{B r}(\mathbf{3}(\mathbf{B r}))$ This compound was prepared following the general procedure described for $2(\mathrm{Br})$ except that $\mathrm{Bu}_{4} \mathrm{NF}(0.030 \mathrm{~g}, 0.115 \mathrm{mmol})$ was used and reacted with $\mathbf{1}(\mathrm{Br})(0.050$ g, $0.030 \mathrm{mmol})$. The air stable violet product $(0.040 \mathrm{~g}, 89 \%$ yield $)$ was characterized as $3(\mathrm{Br})$. ${ }^{31} \mathrm{P}\left\{{ }^{1} \mathrm{H}\right\}$ NMR $\left(\mathrm{CD}_{3} \mathrm{CN}, 121 \mathrm{MHz}\right) \delta=18.3\left(3 \mathrm{P}, \mathrm{d},{ }^{2} \mathrm{~J}_{\mathrm{P}-\mathrm{F}}=50 \mathrm{~Hz}\right) .{ }^{19} \mathrm{~F}\left\{{ }^{1} \mathrm{H}\right\} \mathrm{NMR} \delta=-152.00(3 \mathrm{~F}$, broad signal) ESI-MS $\left(\mathrm{CH}_{3} \mathrm{CN}, 20 \mathrm{~V}\right) \mathrm{m} / \mathrm{z}: 1424.1\left[\mathrm{M}^{+}\right]$. Anal. Calc. $\mathrm{W}_{3} \mathrm{~F}_{3} \mathrm{BrS}_{4} \mathrm{~N}_{3} \mathrm{P}_{3} \mathrm{C}_{42} \mathrm{H}_{48}: \mathrm{C}, 33.5$; H, 3.2; N, 2.8. Found: C, 33.7; H, 3.5; N, $3.1 \%$.

$\left[\mathbf{W}_{3} \mathrm{~S}_{4}(\mathrm{NCS})_{3}(\mathbf{e d p p})_{3}\right] \mathrm{Br}(\mathbf{4}(\mathrm{Br}))$ This compound was prepared following the general procedure described for $2(\mathrm{Br})$ except that $\mathrm{Bu}_{4} \mathrm{NSCN}(0.060 \mathrm{~g}, 0.200 \mathrm{mmol})$ was used and reacted with edpp $(0.050 \mathrm{~g}, 0.030 \mathrm{mmol})$. The air stable blue product $(0.041 \mathrm{~g}, 84 \%$ yield $)$ was characterized as $4(\mathrm{Br})$. ${ }^{31} \mathrm{P}\left\{{ }^{1} \mathrm{H}\right\}$ NMR $\left(\mathrm{CD}_{3} \mathrm{CN}, 121 \mathrm{MHz}\right) \delta=17.8\left(3 \mathrm{P}, \mathrm{s},{ }^{1} \mathrm{~J}_{\mathrm{P}-\mathrm{W}}=96.2 \mathrm{~Hz}\right)$. ESI-MS $\left(\mathrm{CH}_{3} \mathrm{CN}, 20 \mathrm{~V}\right) \mathrm{m} / \mathrm{z}$ : $1540.8\left[\mathrm{M}^{+}\right]$. Anal. Calc. $\mathrm{W}_{3} \mathrm{BrS}_{7} \mathrm{~N}_{6} \mathrm{P}_{3} \mathrm{C}_{45} \mathrm{H}_{48}: \mathrm{C}, 33.3 ; \mathrm{H}, 3.0 ; \mathrm{N}, 5.2$. Found: $\mathrm{C}, 33.7 ; \mathrm{H}, 3.2 ; \mathrm{N}, 5.3$ $\%$.

\section{$X$-ray data collection and structure refinement}

Suitable crystals for X-ray studies of the tetraphenylborate salts of $\mathbf{1}^{+}$were grown by slow vapor diffusion of diethyl ether into a sample solution in $\mathrm{CH}_{3} \mathrm{CN}$. Suitable crystals for X-ray studies of the tetraphenylborate salts of $\mathbf{2}^{+}, \mathbf{3}^{+}$and $\mathbf{4}^{+}$were grown by slow vapor diffusion of diethyl ether into a sample solution in $\mathrm{CH}_{2} \mathrm{Cl}_{2}$. Replacement of the $\mathrm{Br}^{-}$ion was carried out by addition of an excess of $\mathrm{Na}\left(\mathrm{BPh}_{4}\right)$ to methanol solutions of $[\mathbf{1 - 3}](\mathrm{Br})$, resulting in precipitation of the desired tetraphenylborate salts of the $\mathbf{1}^{+}$to $\mathbf{3}^{+}$trinuclear cations. Anion exchange, $\mathrm{Br}^{-}$for $\mathrm{PF}_{6}^{-}$, ion was 
carried out by elution with a $\mathrm{KP}_{6}$ solution in acetone after absorption of a $\mathrm{CH}_{2} \mathrm{Cl}_{2}$ solution of $4[\mathrm{Br}]$ in a silica gel column.

X-ray diffraction experiments were carried out on a Agilent Supernova diffractometer equipped with an Atlas CCD detector using Mo-K $\alpha$ radiation $(\lambda=0.71073 \AA)$ for $[1-3]\left(\mathrm{BPh}_{4}\right)$ and $\mathrm{Cu}-\mathrm{K} \alpha$ radiation $(\lambda=1.54184 \AA)$ for $\mathbf{4}_{2}\left(\mathrm{PF}_{6}\right)_{2}$. No instrument or crystal instabilities were observed during data collection. Absorption corrections based on the multiscan method were applied. ${ }^{38,39}$ The structures were solved by direct methods in SHELXS-97 and refined by the full-matrix method based on $\mathrm{F}^{2}$ with the program SHELXL-97 using the OLEX software package. ${ }^{40,41}$ Details regarding the data collection and refinement parameters are listed in Table 1.

The structure of $1\left(\mathrm{BPh}_{4}\right) \cdot \mathrm{CH}_{3} \mathrm{CN} \cdot \mathrm{CH}_{3} \mathrm{CH}_{2} \mathrm{OCH}_{2} \mathrm{CH}_{3}$ was refined in the triclinic $P-1$ space group. After location of the cluster, eight peaks on general positions remained in the difference Fourier map. These peaks were assigned to carbon, nitrogen and oxygen atoms from acetonitrile and diethylether solvent molecules and refined anisotropically. The structure of $2\left(\mathrm{BPh}_{4}\right) \cdot \mathrm{CH}_{2} \mathrm{Cl}_{2}$ was solved in the triclinic $P-1$ space group. Two out of the six carbon atoms of a phenyl substituent from an aminophosphine ligand shown disorder. These were all refined over two positions with a constraint to the total occupancy of one. A disordered $\mathrm{CH}_{2} \mathrm{Cl}_{2}$ solvent molecule was located in the difference Fourier map where the carbon atom was modelled over two positions with a constraint to the total occupancy of one. The structure of $3\left(\mathrm{BPh}_{4}\right) \cdot \mathrm{CH}_{2} \mathrm{Cl}_{2}$ was refined in the triclinic $P-1$ space group. As in the previous structure, the remaining peaks after location of the cluster and the anion were assigned to carbon and chlorine atoms from a $\mathrm{CH}_{2} \mathrm{Cl}_{2}$ solvent molecule and refined anisotropically. The structure of $\mathbf{4}_{2}\left(\mathrm{PF}_{6}\right)_{2}$ was refined in the trigonal $P 31 \mathrm{c}$ space group and contains two independent clusters per asymmetric unit with the capping sulfur lying on a three fold axis. Disorder was observed on two out of the six carbon atoms of a phenyl substituent from an aminophosphine ligand which were refined over two positions. Disorder was also observed in one sulfur atom of the thiocyanate ligand which was also refined over two positions. These were all refined with a constraint to the total occupancy of one. In all cases, anisotropic displacement parameters were refined for all non-H atoms except for the disordered carbon atoms. The hydrogen 
atoms bonded to carbon were included at their idealized positions and refined as riders with isotropic displacement parameters assigned as 1.2 times the $\mathrm{U}_{\text {eq }}$ value of the corresponding bonding partner. The structural figures were drawn using the Diamond visual crystal structure information system software. $^{42}$

Table 1. Crystallographic data for $[\mathbf{1 - 3}]\left(\mathrm{BPh}_{4}\right)$ and $\mathbf{4}_{2}\left(\mathrm{PF}_{6}\right)_{2}$ cluster salts.

\begin{tabular}{|c|c|c|c|c|}
\hline Compound & $\begin{array}{l}\mathbf{1}\left(\mathrm{BPh}_{4}\right) \cdot\left(\mathrm{CH}_{3} \mathrm{CN}\right) \cdot \\
\left(\mathrm{CH}_{3} \mathrm{CH}_{2} \mathrm{OCH}_{2} \mathrm{CH}_{3}\right)\end{array}$ & $\mathbf{2}\left(\mathrm{BPh}_{4}\right) \cdot\left(\mathrm{CH}_{2} \mathrm{Cl}_{2}\right)$ & $3\left(\mathrm{BPh}_{4}\right) \cdot\left(\mathrm{CH}_{2} \mathrm{Cl}_{2}\right)$ & $\mathbf{4}_{2}\left(\mathrm{PF}_{6}\right)_{2}$ \\
\hline Empirical formula & $\mathrm{C}_{72} \mathrm{H}_{71} \mathrm{BBr}_{3} \mathrm{~N}_{4} \mathrm{OP}_{3} \mathrm{~S}_{4} \mathrm{~W}_{3}$ & $\mathrm{C}_{67} \mathrm{H}_{66} \mathrm{BCl}_{5} \mathrm{~N}_{3} \mathrm{P}_{3} \mathrm{~S}_{4} \mathrm{~W}_{3}$ & $\mathrm{C}_{67} \mathrm{H}_{70} \mathrm{BCl}_{2} \mathrm{~F}_{3} \mathrm{~N}_{3} \mathrm{P}_{3} \mathrm{~S}_{4} \mathrm{~W}_{3}$ & $\mathrm{C}_{90} \mathrm{H}_{66} \mathrm{~F}_{12} \mathrm{~N}_{12} \mathrm{P}_{8} \mathrm{~S}_{14} \mathrm{~W}_{6}$ \\
\hline Formula weight & 2031.57 & 1873.99 & 1828.67 & 3343.25 \\
\hline Crystal system & Triclinic & Triclinic & Triclinic & Trigonal \\
\hline$a, \AA$ & $14.1815(5)$ & $13.6639(3)$ & $14.2869(3)$ & $16.3126(3)$ \\
\hline$b, \AA$ & $14.9361(5)$ & $15.5155(3)$ & $15.6823(3)$ & $16.3126(3)$ \\
\hline$c, \AA$ & $20.2894(7)$ & $18.3338(3)$ & $17.6782(3)$ & $27.3343(4)$ \\
\hline$\alpha,{ }^{\circ}$ & $101.274(3)$ & $100.7043(14)$ & $75.7547(14)$ & 90.00 \\
\hline$\beta,{ }^{\circ}$ & $105.565(3)$ & $100.8016(14)$ & $71.0168(16)$ & 90.00 \\
\hline$\gamma,{ }^{o}$ & $105.842(3)$ & $108.1880(17)$ & $65.3500(17)$ & 120.00 \\
\hline$V, \AA^{3}$ & $3811.6(2)$ & $3500.73(10)$ & $3375.90(10)$ & $6299.22(18)$ \\
\hline$T, \mathrm{~K}$ & $199.95(10)$ & $200.00(10)$ & $199.95(10)$ & 293(2) \\
\hline Space group & $P-1$ & $P-1$ & $P-1$ & $P 31 \mathrm{c}$ \\
\hline$Z$ & 2 & 2 & 2 & 2 \\
\hline$\mu($ Mo K $\alpha), \mathrm{mm}^{-1}$ & 6.304 & 5.337 & 5.424 & --- \\
\hline$\mu(\mathrm{Cu} \mathrm{K} \alpha), \mathrm{mm}^{-1}$ & --- & --- & ----- & 13.481 \\
\hline $\begin{array}{l}\text { Reflections } \\
\text { collected }\end{array}$ & 40721 & 58146 & 63675 & 36371 \\
\hline $\begin{array}{l}\text { Unique } \\
\text { reflections } / R_{\text {int }}\end{array}$ & $13412 / 0.0452$ & $13744 / 0.0300$ & $11862 / 0.0430$ & $8136 / 0.0687$ \\
\hline $\begin{array}{l}\text { Goodness-of-fit } \\
\text { (GOF) on } F^{2}\end{array}$ & 1.073 & 1.132 & 1.068 & 1.134 \\
\hline $\begin{array}{l}R_{1}^{[\mathrm{a}]} / w R_{2}^{[\mathrm{b}]} \text { (all } \\
\text { data) }\end{array}$ & $0.0417 / 0.0922$ & $0.0429 / 0.0840$ & $0.0302 / 0.0613$ & $0.0485 / 0.1257$ \\
\hline Residual $\rho / \mathrm{e}^{-3}$ & $2.73 /-0.89$ & $1.77 /-1.76$ & $1.62 /-0.93$ & $0.92 /-0.58$ \\
\hline
\end{tabular}




\section{Kinetic Experiments}

The kinetic experiments were carried out with an Applied Photophysics SX-17MV stopped-flow spectrometer provided with a PDA1 photodiode array (PDA) detector. All experiments were carried out at $25.0{ }^{\circ} \mathrm{C}$. The reactions of $\left[\mathrm{W}_{3} \mathrm{~S}_{4} \mathrm{X}_{3}(\mathrm{PN})_{3}\right] \mathrm{Br}\left(\mathrm{X}=\mathrm{Br}^{-}\left(\mathbf{1}^{+}\right), \mathrm{Cl}^{-}\left(\mathbf{2}^{+}\right), \mathrm{F}^{-}\left(\mathbf{3}^{+}\right), \mathrm{NCS}^{-}\left(\mathbf{4}^{+}\right)\right)$clusters $\left(\sim 2 \times 10^{-4} \mathrm{M}\right)$ (with different entering ligands $\left(\mathrm{Cl}^{-}, \mathrm{Br}^{-}, \mathrm{F}^{-}, \mathrm{NCS}^{-}\right)$have been studied using acetonitrile as solvent. We have used a range of concentrations between $8.3 \times 10^{-3}-0.05 \mathrm{M}$. Measurements were performed in the presence of ionic strength $0.05 \mathrm{M}$. In each case a salt of halide $\left(\mathrm{X}^{-}\right.$of complex) was used. We found that the results were similar with or without added salt but the quality of fits was better if it was not present. In all cases the spectral changes were measured over a wide wavelength range and analyzed with the Specfit program ${ }^{43}$ using the kinetic models indicated in the corresponding section.

\section{DFT calculations}

The calculations have been conducted with the Becke hybrid density functional (B3LYP) ${ }^{44}$ method as implemented in the Gaussian 09 program suite. ${ }^{45}$ The double- $\xi$ pseudo-orbital basis set LanL2DZ, in which $\mathrm{W}, \mathrm{H}, \mathrm{C}, \mathrm{N}, \mathrm{P}, \mathrm{S}, \mathrm{F}, \mathrm{Cl}$ and $\mathrm{Br}$ are represented the relativistic core LanL2 potential of Los Alamos, was used. B3LYP/LanL2DZ has been proved to be a reliable tool for describing geometric, electronic structures and energetic profiles of $\mathrm{M}_{3} \mathrm{~S}_{4}(\mathrm{M}=\mathrm{Mo}, \mathrm{W})$ clusters. ${ }^{16,46,47}$ The three Potential Energy Surfaces for the substitution of one of the bromides of $\mathbf{1}^{+}$by the entering ligands have been obtained in each case by constructing a grid varying the $\mathrm{W}-\mathrm{Br}$ and $\mathrm{W}-\mathrm{X}$ distances, and fully optimizing the remaining geometric parameters. In the three cases, the $\mathrm{W}-\mathrm{Br}$ distance has been varyied from the bonding distance $(2.72 \AA)$ to $4.72 \AA$ in $0.2 \AA$ steps. On the other hand, the W-X distances have been increased $2 \AA$ starting from the corresponding bonding distances $(2.02 \AA$ for WF; $2.55 \AA$ for $\mathrm{W}-\mathrm{Cl}$ and $2.04 \AA$ for $\mathrm{W}-\mathrm{NCS})$ in $0.2 \AA$ steps. Therefore, a total of $11 \mathrm{x} 11$ points, i. e., 121 points, have been calculated to construct each Potential Energy Surface. The geometry optimizations have been first performed in gas phase without any symmetry constraint followed by analytical frequency calculations to confirm that a minimum or a transition state has been reached. 
The nature of the species connected by a given transition state structure has been checked by calculating the Intrinsic Reaction Coordinate (IRC) pathway ${ }^{48}$, that assures the Transition Structure (TS) connections to the reactant and product complexes following the transition vector downhill from the corresponding TS. Taking the calculated gas phase structures as starting points, we have also conducted geometry optimizations without any constraints by using the Polarizable Continuum Model (PCM) approach ${ }^{49,50}$, to include the acetonitrile solvent effect in the geometries and energies. We have considered electronic energies and Gibbs free energies for discussion. The latter have been obtained by means of frequency calculations at room temperature of the stationary points found.

\section{Results and Discussion}

\section{Synthesis, molecular structure and reactivity}

Excision reaction of the $\left\{\mathrm{W}_{3} \mathrm{~S}_{7} \mathrm{Br}_{4}\right\}_{\mathrm{n}}$ polymeric phases with an excess of (2aminoethyl)diphenylphosphine (edpp), $\mathrm{PPh}_{2}\left(\mathrm{CH}_{2}\right)_{2} \mathrm{NH}_{2}$, in acetonitrile in the presence of $\mathrm{HBr}$ (see eq. 1) affords only one among all possible isomers of formula $\left[\mathrm{W}_{3} \mathrm{~S}_{4} \mathrm{Br}_{3}(\text { edpp })_{3}\right]^{+}, \mathbf{1}^{+}$, in a single synthetic step and good yields, ca. $60 \%$.

$$
\left\{\mathrm{W}_{3} \mathrm{~S}_{7} \mathrm{Br}_{4}\right\}_{\mathrm{n}}+6 \mathrm{PPh}_{2}\left(\mathrm{CH}_{2}\right)_{2} \mathrm{NH}_{2}(\mathrm{edpp}) \stackrel{\mathrm{HBr}}{\longrightarrow}\left[\mathrm{W}_{3} \mathrm{~S}_{4} \mathrm{Br}_{3}(\mathrm{edpp})_{3}\right] \mathrm{Br}+3 \mathrm{SPPh}_{2}\left(\mathrm{CH}_{2}\right)_{2} \mathrm{NH}_{2}
$$

The substitutional reactivity of the $\mathrm{W}-\mathrm{Br}$ bond in $\left[\mathrm{W}_{3} \mathrm{~S}_{4} \mathrm{Br}_{3}(\mathrm{edpp})_{3}\right]^{+}$towards halide and pseudohalide (eq. 2) salts has allowed us to prepare and fully characterize also the fluoride, chloride and thiocyanate tungsten derivatives of formula $\left[\mathrm{W}_{3} \mathrm{~S}_{4} \mathrm{X}_{3}(\mathrm{edpp})_{3}\right]^{+}(\mathrm{X}=\mathrm{F}, \mathrm{Cl}, \mathrm{NCS})$ in high yields.

$$
\left[\mathrm{W}_{3} \mathrm{~S}_{4} \mathrm{Br}_{3}(\mathrm{edpp})_{3}\right] \mathrm{Br}+3 \mathrm{X}^{-} \longrightarrow\left[\mathrm{W}_{3} \mathrm{~S}_{4} \mathrm{X}_{3}(\mathrm{edpp})_{3}\right] \mathrm{Br}+3 \mathrm{Br}^{-}
$$

The structures of cations $\left.\left[\mathrm{W}_{3} \mathrm{~S}_{4} \mathrm{Br}_{3}(\mathrm{edpp})_{3}\right]^{+}\left(\mathbf{1}^{+}\right),\left[\mathrm{W}_{3} \mathrm{~S}_{4} \mathrm{Cl}_{3}(\mathrm{edpp})_{3}\right]^{+}\left(\mathbf{2}^{+}\right), \mathrm{W}_{3} \mathrm{~S}_{4} \mathrm{~F}_{3}(\mathrm{edpp})_{3}\right]^{+}$ $\left(3^{+}\right)$and $\left[\mathrm{W}_{3} \mathrm{~S}_{4}(\mathrm{NCS})_{3}(\mathrm{edpp})_{3}\right]^{+}\left(4^{+}\right)$have been determined by single crystal X-ray diffraction as their tetraphenylborate or hexafluorophosphate salts and they share identical structural features. The 
four cations contain the incomplete cuboidal $\mathrm{W}_{3} \mathrm{~S}_{4}$ cluster unit which results from the reduction of the disulfide bridges present in the starting bromide polymeric material to sulfides. In this unit, tungsten and sulphur atoms occupy adjacent vertices in a cube with a metal position missing, which results in an incomplete cubane-type structure. Figure 3 shows two ORTEP views of the $\mathbf{1}^{+}$cation. In $\mathbf{4}^{+}$, the three outer thiocyanate ligands occupy the halide positions in $\mathbf{1}^{+}$to $\mathbf{3}^{+}$, and coordinate the metal through the nitrogen atom. Packing of $4\left(\mathrm{PF}_{6}\right)$ occurs with two crystallographycally independent trimetallic cluster units and short NCS...HN contacts $(2.420 \AA)$ between the sulphur atom of a thiocyanate ligand on one cluster and the hydrogen atom of the amino group of the adjacent cluster. Table 2 contains a list of the most important averaged bond lengths for the $\mathbf{1}^{+}$to $\mathbf{4}^{+}$ cations together with those reported for the $\left[\mathrm{W}_{3} \mathrm{~S}_{4} \mathrm{Br}_{3}(\mathrm{dmpe})_{3}\right]^{+}$cation for comparative purposes. ${ }^{51}$ The three metal atoms define an approximately equilateral triangle with $\mathrm{W}-\mathrm{W}$ bond distances of $2.7520[3] \AA$ for $\mathbf{1}^{+}, 2.7495[3] \AA$ for $\mathbf{2}^{+}, 2.7357[3] \AA$ for $\mathbf{3}^{+} 2.7507[11] \AA$ for $\mathbf{4}^{+}$, in agreement with the presence of a single metal-metal bond. The nature of $\mathrm{W}\left(\mu_{3}-\mathrm{S}\right)\left(\mu_{3}-\mathrm{S}\right)_{3}$ is such that the bridging and capping sulphur atoms occupy a set of facial positions around the pseudo octahedrally coordinated metal atoms leaving the three outer facial sites available for the phosphorous and nitrogen atoms of the aminophosphine and a site occupied by the halide ligand. Remarkably, as previously mentioned, only one isomer is formed with all three nitrogen atoms of the amino groups located trans to the bridging sulphur atoms, the three phosphorous atoms being placed trans to the capping sulphur. A similar situation is found in $\mathrm{M}_{3} \mathrm{Cl}_{4}\left(\mathrm{H}_{2} \mathrm{O}\right)_{2}\left(\mathrm{PPh}_{3}\right)_{3}$ complexes that result from the substitution of the water molecules in acidic $\mathrm{HCl}$ solutions of the $\left[\mathrm{M}_{3} \mathrm{~S}_{4}\left(\mathrm{H}_{2} \mathrm{O}\right)_{9}\right]^{4+}$ aquo ions by $\mathrm{PPh}_{3}{ }^{52}$ Kinetic studies by Sykes and coworkers evidence different labilities for the three outer metal positions present in the $\left[\mathrm{M}_{3} \mathrm{~S}_{4}\left(\mathrm{H}_{2} \mathrm{O}\right)_{9}\right]^{4+}$ aquo ions with the two positions trans to the bridging sulfur being $10^{5}$ times more labile than that trans to the capping sulfur. ${ }^{34}$ In the $\mathrm{M}_{3} \mathrm{~S}_{4}$ system, the ligands harder atoms have a tendency to occupy the more labile positions so the nitrogen atom of the aminophosphine locates trans to the bridging sulfur. Therefore, nitrogen and halogen atoms coordinated to the same metal center are found on the same side of the trimetallic plane, as shown in Figure 3 (bottom) with $\mathrm{X} \bullet \bullet \mathrm{N}$ distances of $3.021 \AA$ for $\mathbf{1}^{+}, 3.015 \AA$ for $\mathbf{2}^{+}, 2.723$ for $\mathbf{3}^{+}$and 2.728 for 
$\mathbf{4}^{+}$. However, the shorter $\mathrm{X} \bullet \bullet \mathrm{H}(-\mathrm{N})$ distances in $\mathbf{1}^{+}$and $\mathbf{2}^{+}$correspond to $\mathrm{X} \bullet \bullet \mathrm{H}$ interactions between halogen atoms and amino groups on adjacent metals with values ranging from 2.745 to $2.859 \AA$ for $\mathbf{1}^{+}$and 2.529 to $3.048 \AA$ for $\mathbf{2}^{+} \cdot$ In the case of fluorocomplex $\mathbf{3}^{+}$the above $\mathrm{X} \cdot \bullet \mathrm{H}(-\mathrm{N})$ distances (2.469 to $2.829 \AA$ ) are comparable to $\mathrm{X} \bullet \bullet \cdot \mathrm{H}(-\mathrm{N})$ interactions between halogen atoms and amino groups on the same metal center with values ranging from 2.464 to $2.673 \AA$ A. For the cluster cation $4^{+}$ the shorter $\mathrm{X} \cdot \bullet \cdot \mathrm{H}(-\mathrm{N})$ distances correspond to interactions between nitrogen atoms $\left(\mathrm{NCS}^{-}\right.$ligand) and amino groups on the same metal center with values ranging from 2.661 to $2.665 \AA$.
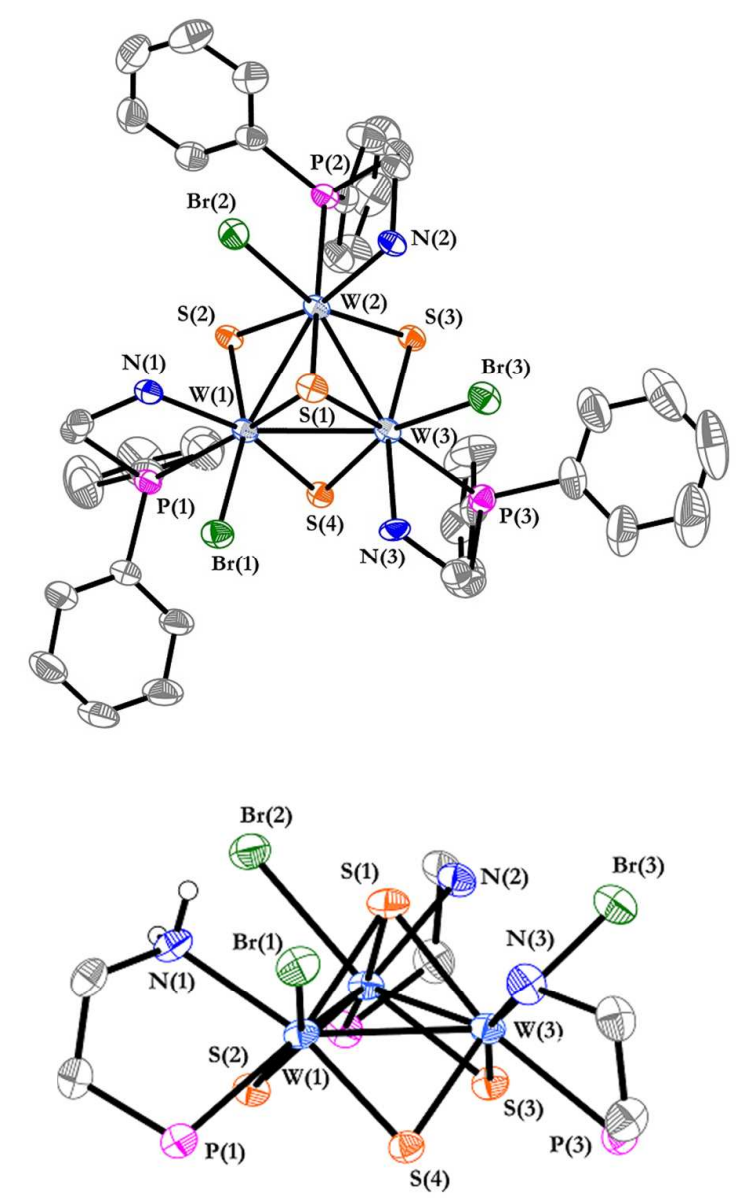

Figure 3. ORTEP representations of two different views of the $\mathbf{1}^{+}$cation (ellipsoids $50 \%$ probability). In the view at top, the hydrogen atoms have been omitted for clarity. In the view at bottom, phenyl rings and hydrogen atoms, except those directly bonded to N(1), have been also omitted to emphasize the halogen and $\mathrm{H}_{2}-\mathrm{N}$ orientations. 
The solid state structure of complexes $\mathbf{1}^{+}-\mathbf{4}^{+}$is preserved in solution as evidenced by their ${ }^{31} \mathrm{P}\left\{{ }^{1} \mathrm{H}\right\}$ NMR spectra registered in $\mathrm{CD}_{3} \mathrm{CN}$, which shows a single signal at $15.2 \mathrm{ppm}$ for $\mathbf{1}^{+}, 18.1$ ppm for $\mathbf{2}^{+}$and $17.8 \mathrm{ppm}$ for $\mathbf{4}^{+}$, in agreement with the presence of three equivalent phosphorous nuclei. The $\mathbf{3}^{+}$phosphorous signal appears as a doublet centered at $18.3\left({ }^{2} \mathrm{~J}_{\mathrm{P}-\mathrm{F}}=50 \mathrm{~Hz}\right) \mathrm{ppm}$ as a result of coupling between phosphorous and fluorine nuclei. The ESI mass spectra of the halide amoniphosphine complexes shows one peak centered at $1607.9 \mathrm{~m} / \mathrm{z}$ for $\mathbf{1}^{+}, 1474.0 \mathrm{~m} / \mathbf{z}$ for $\mathbf{2}^{+}$, $1424.1 \mathrm{~m} / \mathrm{z}$ for $\mathbf{3}^{+}$and $1540.8 \mathrm{~m} / \mathrm{z}$ for $\mathbf{4}^{+}$attributed to the pseudomolecular cations on the basis of the $\mathrm{m} / \mathrm{z}$ value and its characteristic isotopic pattern. As for the family of $\left(\left[\mathrm{M}_{3} \mathrm{Q}_{4} \mathrm{X}_{3}(\text { diphosphine })_{3}\right]^{+}\right.$ $(\mathrm{M}=\mathrm{Mo}, \mathrm{W} ; \mathrm{Q}=\mathrm{S}, \mathrm{Se}$ and $\mathrm{X}=\mathrm{F}, \mathrm{Cl}, \mathrm{Br}$ and $\mathrm{H})$ complexes, this spectrometric technique has been very useful for the characterization of the new aminophosphine cluster complexes.

Reactivity studies show that substitution of the bromides in $\mathbf{1}^{+}$by $\mathrm{Cl}^{-}$and $\mathrm{NCS}^{-}$easily occurs at room temperature, which contrasts with earlier observations in the diphosphino $\mathrm{W}_{3} \mathrm{~S}_{4}$ system, for which no reaction is observed. ${ }^{53}$ Only substitution of bromide by fluoride occurs for both the diphosphino and aminophosphino $(\mathrm{L})$ trimetallic $\left[\mathrm{W}_{3} \mathrm{~S}_{4} \mathrm{Y}_{3} \mathrm{~L}_{3}\right]^{+}$clusters.

Table 2. Selected averaged bond distances $(\AA)$ for $[1-3]\left(\mathrm{BPh}_{4}\right), 4\left(\mathrm{PF}_{6}\right)$ and $\left[\mathrm{W}_{3} \mathrm{~S}_{4} \mathrm{Br}_{3}(\mathrm{dmpe})_{3}\right]\left(\mathrm{PF}_{6}\right)$.

\begin{tabular}{l|cclcc}
\hline Length $(\AA)^{\mathrm{a}}$ & {$\left[\mathrm{W}_{3} \mathrm{~S}_{4} \mathrm{Br}_{3}(\mathrm{dmpe})_{3}\right]\left(\mathrm{PF}_{6}\right)^{51}$} & $\mathbf{1}\left(\mathrm{BPh}_{4}\right)$ & $\mathbf{2}\left(\mathrm{BPh}_{4}\right)$ & $\mathbf{3}\left(\mathrm{BPh}_{4}\right)$ & $\mathbf{4}\left(\mathrm{PF}_{6}\right)$ \\
\hline $\mathrm{W}-\mathrm{W}$ & $2.759(2)$ & $2.7520[3]$ & $2.7495[3]$ & $2.7357[3]$ & $2.7507[11]$ \\
$\mathrm{W}-\mu_{3}-\mathrm{S}(1)$ & $2.37(1)$ & $2.3450[16]$ & $2.3715[15]$ & $2.3769[13]$ & $2.371[3]$ \\
$\mathrm{W}-\mu-\mathrm{S}(2)^{\mathrm{b}}$ & $2.30(1)$ & $2.3117[15]$ & $2.3104[15]$ & $2.3140[13]$ & $2.315[3]$ \\
$\mathrm{W}-\mu-\mathrm{S}(2)^{\mathrm{c}}$ & $2.33(1)$ & $2.3091[15]$ & $2.3040[15]$ & $2.3066[13]$ & $2.298[3]$ \\
$\mathrm{W}-\mathrm{P}(1)^{\mathrm{d}}$ & $2.51(1)$ & $2.5306[16]$ & $2.5408[17]$ & $2.5264[14]$ & $2.542[4]$ \\
$\mathrm{W}-\mathrm{N}$ & - & $2.286[5]$ & $2.268[5]$ & $2.267[4]$ & $2.276[11]$ \\
$\mathrm{W}-\mathrm{X}(\mathrm{X}=\mathrm{F}, \mathrm{Cl}, \mathrm{Br}$, & $2.641(4)$ & $2.6401[7]$ & $2.4947[16]$ & $2.043[4]$ & $2.114[10]$ \\
$\mathrm{NCS})$ & & & & & \\
\hline
\end{tabular}




\begin{abstract}
${ }^{a}$ Standard deviations for averaged values are given in square brackets. ${ }^{\mathrm{b}} \mathrm{W}-\mu-\mathrm{S}$ distance trans to W$\mathrm{X}$ bond. ${ }^{\mathrm{c}} \mathrm{W}-\mu-\mathrm{S}$ distance trans to W-P $\left(\left[\mathrm{W}_{3} \mathrm{~S}_{4} \mathrm{Br}_{3}(\mathrm{dmpe})_{3}\right]^{+}\right)$or W-N $\left([1-3]\left(\mathrm{BPh}_{4}\right)\right)$ bond. ${ }^{\mathrm{d}}$ Distance trans to the $\mathrm{W}-\left(\mu_{3}-\mathrm{S}\right)$ bond.
\end{abstract}

The reactions of $\mathbf{1}^{+}$with halide and pseudohalide salts were monitored by ESI mass spectrometry and ${ }^{31} \mathrm{P}\left\{{ }^{1} \mathrm{H}\right\} \mathrm{NMR}$, and the sequential substitution of bromide by chloride, fluoride or thiocyanate ligands was observed. Thus, in the case of the reaction between $\mathbf{1}^{+}$and $\mathrm{Cl}^{-}$, the sequential substitution of the terminal ligands is demonstrated by the appearance of peaks at $\mathrm{m} / \mathrm{z}$ : 1563.7, 1517.8 and 1474.0 in the ESI-MS monitoring for $\left[\mathrm{W}_{3} \mathrm{~S}_{4} \mathrm{Br}_{2} \mathrm{Cl}(\mathrm{edpp})_{3}\right]^{+},\left[\mathrm{W}_{3} \mathrm{~S}_{4} \mathrm{BrCl}_{2}(\mathrm{edpp})_{3}\right]^{+}$ and $\left[\mathrm{W}_{3} \mathrm{~S}_{4} \mathrm{Cl}_{3}(\mathrm{edpp})_{3}\right]^{+}$, respectively (Figure 4). Similar conclusions are obtained by monitoring the reaction with phosphorus NMR. The results are summarized in Figure 5 and they show that conversion of $\mathbf{1}^{+}$to $\mathbf{2}^{+}$occurs with formation of two reaction intermediates. However, whereas the spectra of the starting complex and the reaction product consist of a single signal (A and D, respectively, in Figure 5), the spectra of the intermediate contain three signals, labelled B for the first intermediate and $\mathrm{C}$ for the second, which indicates that the three edpp ligands are no longer equivalent in the $\left[\mathrm{W}_{3} \mathrm{~S}_{4} \mathrm{Br}_{2} \mathrm{Cl}(\mathrm{edpp})_{3}\right]^{+}$and $\left[\mathrm{W}_{3} \mathrm{~S}_{4} \mathrm{BrCl}_{2}(\mathrm{edpp})_{3}\right]^{+}$intermediates. The facile substitution at room temperature of the bromide ligand in $\mathbf{1}^{+}$by other halides and pseudohalides is a distinctive feature of the $\mathrm{W}_{3} \mathrm{~S}_{4}$ aminophosphino complexes in comparison with its diphosphino analogues.

Quite similar results are also observed during the reaction of $\mathbf{1}^{+}$with $\mathrm{F}^{-}$and $\mathrm{NCS}^{-}$; the positions of the NMR signals are shown in Table 3. For the reaction with fluoride, the phosphorus spectra are complicated by the existence of coupling with the coordinated fluorides, which leads to splitting of the signals that hinder a detailed assignment of the signals for the different intermediates. In any case, a doublet was observed for the tri-substituted species with a P-F coupling constant of $50 \mathrm{~Hz}$. Interestingly, the ${ }^{19} \mathrm{~F}\left\{{ }^{1} \mathrm{H}\right\}$ spectrum shows a broad signal centered at $-152 \mathrm{ppm}$, and the coupling with the phosphorus nuclei could not be resolved even at low temperature. Broadening of the ${ }^{19} \mathrm{~F}\left\{{ }^{1} \mathrm{H}\right\} \quad$ NMR signal in fluorido complexes containing nitrogen donor ligands is not 
unprecedented, ${ }^{54}$ and it could be associated in the present case to some interaction of coordinated fluoride with the neighboring amino groups. It must be also noted that, in addition to the signals in Table 3, the NMR spectra recorded at long reaction times usually reveal the appearance of a series of less intense signals at 30-40 ppm which probably correspond to some secondary or decomposition product.

c)

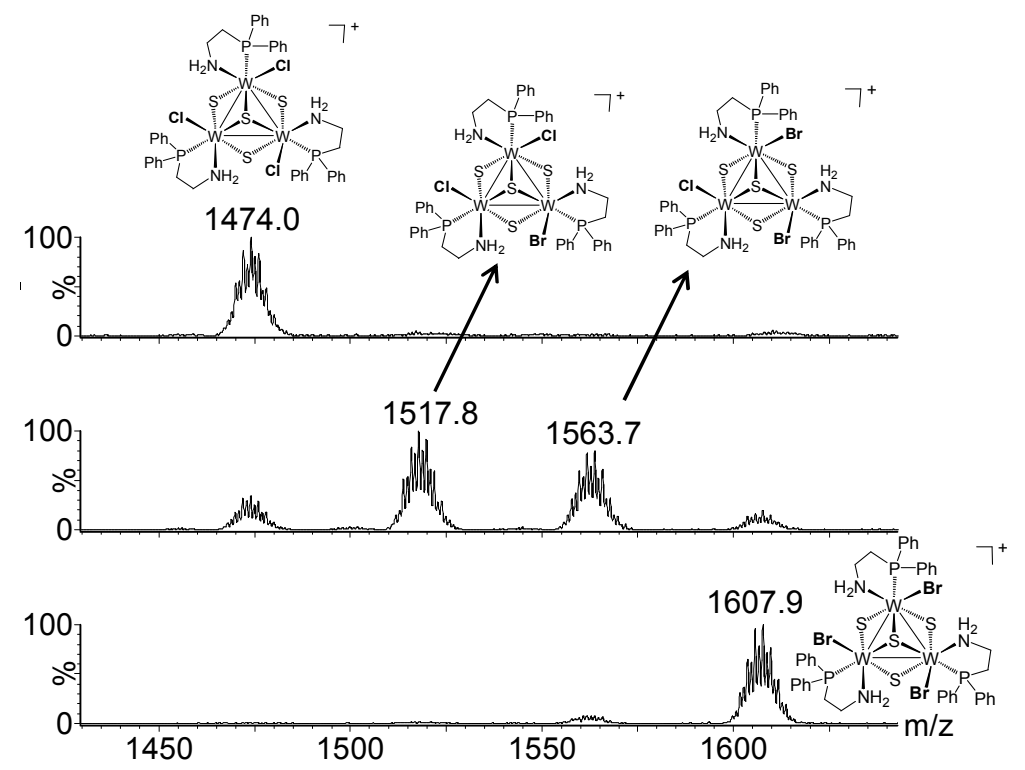

Figure 4. ESI-MS monitoring of the reaction between $\mathbf{1}^{+}$and $\mathrm{Pr}_{4} \mathrm{NCl}$ a) Initial time, b) After 3 min. c) after $1 \mathrm{~h}$. 

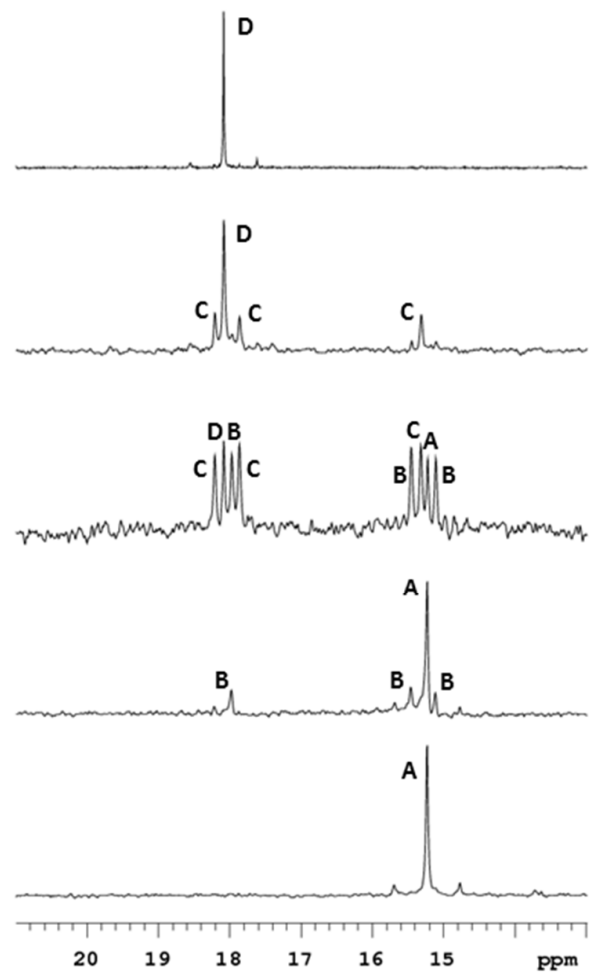

Figure 5. ${ }^{31} \mathrm{P}\left\{{ }^{1} \mathrm{H}\right\}$ NMR spectra of $\mathbf{1}^{+}(\mathrm{A}), \mathrm{I}_{1}(\mathrm{~B}), \mathrm{I}_{2}(\mathrm{C})$ and $\mathbf{2}^{+}(\mathrm{D})$ in the sequential reaction with $\mathrm{Pr}_{4} \mathrm{NCl}$ in acetonitrile- $\mathrm{d}_{3}$. The spectra were obtained through the addition of successive aliquots of a solution of the chloride salt.

Table 3 lists the ${ }^{31} \mathrm{P}\left\{{ }^{1} \mathrm{H}\right\}$ chemical shifts for the species formed in the reaction of $\mathbf{1}^{+}$with different incoming ligands and gives support to the formation of two intermediates between $\mathbf{1}^{+}$, with three $\mathrm{W}-\mathrm{Br}$ bonds, and the reaction product, with three $\mathrm{W}-\mathrm{X}$ bonds. For a given intermediate, the number of signals with chemical shifts close to that observed for $\mathbf{1}^{+}(15.2 \mathrm{ppm})$ coincides with the number of $\mathrm{Br}$ ligands in the intermediate, i.e. two for the first intermediate and one for the second, which suggests that those signals correspond to the edpp ligands coordinated to the metal centres with unreacted $\mathrm{W}-\mathrm{Br}$ bonds. In agreement, the remaining signals of the intermediates correspond to PN ligands coordinated to metal centres with $\mathrm{W}-\mathrm{X}$ bonds and they appear at chemical shifts closer to that observed for the trisubstituted $\mathrm{W}-\mathrm{X}$ reaction product. It is also interesting to note that the symmetry is recovered and the three edpp ligands become equivalent again once the reaction is completed with substitution at the third metal centre, which indicates that all the edpp ligands retain their original disposition, with the three $\mathrm{P}$ donors at the same site of the plane defined by the three 
metal centres. From the mechanistic point of view, this indicates that the entering ligand approaches to the metal centre at the proximities of the $\mathrm{W}-\mathrm{Br}$ bond, the entering ligand occupying finally the coordination site initially occupied by the leaving bromide.

Some experiments similar to those described above but using other starting complexes were also carried out. Those experiments showed that the $\mathbf{3}^{+}$fluorocomplex does not react with an excess of any of the other three entering ligands $\left(\mathrm{Cl}^{-}, \mathrm{Br}^{-}\right.$or $\left.\mathrm{NCS}^{-}\right)$, which suggests that it is the most stable from the thermodynamic point of view. In agreement with that conclusion, both $\mathbf{2}^{+}$and $\mathbf{4}^{+}$were found to react with an excess of fluoride. More details are given below when commenting the kinetic results.

Table 3. Chemical shifts of the ${ }^{31} \mathrm{P}\left\{{ }^{1} \mathrm{H}\right\}$ signals in ppm in $\mathrm{CD}_{3} \mathrm{CN}$ at $25.0^{\circ} \mathrm{C}$ for the species formed in the reaction of $\mathbf{1}^{+}$with different incoming ligands.

\begin{tabular}{c|cccc}
\hline $\mathbf{X}$ & $\mathbf{W}_{\mathbf{3}} \mathbf{B r}_{\mathbf{3}}$ & $\mathbf{W}_{\mathbf{3}} \mathbf{B} \mathbf{r}_{\mathbf{2}} \mathbf{X}$ & $\mathbf{W}_{\mathbf{3}} \mathbf{B r} \mathbf{X}_{\mathbf{2}}$ & $\mathbf{W}_{\mathbf{3}} \mathbf{X}_{\mathbf{3}}$ \\
\hline $\mathrm{Cl}^{-}$ & 15.2 & $15.1,15.4,18.0$ & $15.3,17.9,18.2$ & 18.1 \\
$\mathrm{NCS}^{-}$ & & $(15.2,15.4)^{[\mathrm{a}]}, 18.0$ & $(15.4)^{[\mathrm{a}]}, 17.6,18.1$ & 17.8 \\
$\mathrm{~F}^{-}$ & {$[\mathrm{b}]$} & {$[\mathrm{b}]$} & 18.3 \\
& & & $\left({ }^{2} \mathrm{~J}_{\mathrm{F}, \mathrm{P}}=50 \mathrm{~Hz}\right)$ \\
\hline
\end{tabular}

${ }^{\text {[a] }}$ These signals are overlapped with those of the starting material and the other intermediate. ${ }^{[\mathrm{b}]}$ It has not been possible to assign the signals corresponding to the reaction intermediates as broad unresolved signals are observed.

\section{The kinetics of substitution reactions}


The kinetics of the reactions of $\left[\mathrm{W}_{3} \mathrm{~S}_{4} \mathrm{X}_{3}(\mathrm{edpp})_{3}\right] \mathrm{Br}\left(\mathrm{X}=\mathrm{Br}^{-}, \mathrm{Cl}^{-}, \mathrm{F}^{-}, \mathrm{NCS}^{-}\right)$clusters with an excess of the different entering ligands $\left(\mathrm{Cl}^{-}, \mathrm{Br}^{-}, \mathrm{F}^{-}, \mathrm{NCS}^{-}\right)$was studied in acetonitrile. In general, the spectral changes observed under pseudo first order conditions for the reactions in eq (3) show that conversion of the starting complex to the trisubstituted compound occurs within the time scale of the stoppedflow technique, although in most cases there are additional slower changes that surely correspond to the secondary or decomposition process also detected in the ESI-MS and NMR studies. In agreement with the NMR observations commented above, the trifluoro cluster $\mathbf{3}^{+}$did not show substitution reactions with any of the other ligands because of its higher stability. The kinetics of interconversion between the tribromo and trichloro complexes $\left(\mathbf{1}^{+}\right.$and $\left.\mathbf{2}^{+}\right)$could not be studied because the spectral changes are very small and overlap with those for secondary processes, so that all attempts to analyze the kinetic data led to unreproducible results.

$$
\left[\mathrm{W}_{3} \mathrm{~S}_{4} \mathrm{X}_{3}(\mathrm{edpp})_{3}\right] \mathrm{Br}+3 \mathrm{Y}^{-} \longrightarrow\left[\mathrm{W}_{3} \mathrm{~S}_{4} \mathrm{Y}_{3}(\mathrm{edpp})_{3}\right] \mathrm{Br}+3 \mathrm{X}^{-}
$$

As an example of the reactions studied, the spectral changes observed for the reaction of $\mathbf{1}^{+}$ with $\mathrm{F}^{-}$are illustrated in Figure 6, and other cases are included in the Supporting Information. In general, the changes can be satisfactory fitted to a kinetic model with a single exponential $(A \rightarrow B)$, the fit leading to calculated spectra of A and B that agree well with those recorded for solutions of the corresponding $\mathbf{1}^{+}$to $\mathbf{4}^{+}$clusters. The observation of a single kinetic step for the overall process of sequential reaction at the three metal centres is quite common in kinetic studies on reactions of this kind of compounds, and it can be rationalized by considering that the process occurs with statistically-controlled kinetics. ${ }^{4,16,33,35}$ Thus, if the three metal centres behave independently of each other, the rates of substitution of the three X monodentate ligands in Figure 2 will be controlled by the statistics and three consecutive kinetic steps with rate constants in 3:2:1 ratio must be expected. However, if in addition the three metal centres behave as independent chromophores, there is a simplification of rate law and the kinetic traces only show a single resolvable step. The requirements for this simplification of the kinetics have been discussed recently, as well as the reasons leading to possible deviations from the statistical behavior. ${ }^{55}$ 


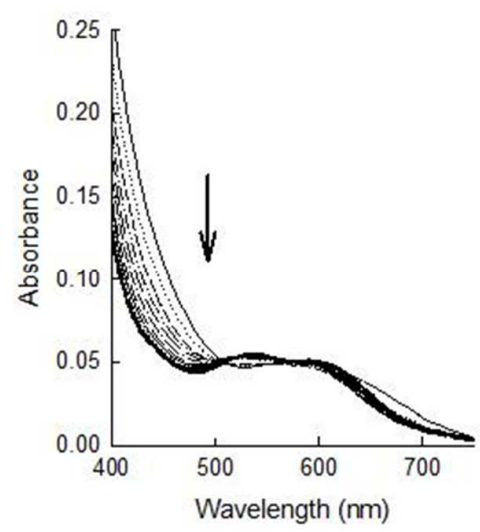

Figure 6. Typical spectral changes for the reaction of $\mathbf{1}^{+}$with $\mathrm{Bu}_{4} \mathrm{NF}$ to yield $\mathbf{3}^{+}$in acetonitrile at $25.0^{\circ} \mathrm{C}$ (cluster concentration $=5 \times 10^{-5} \mathrm{M},\left[\mathrm{Bu}_{4} \mathrm{NF}\right]=0.025 \mathrm{M}$, experiment time $=0.4 \mathrm{seg}$ ).

The dependence of the values of the observed rate constant $k_{\mathrm{obs}}$ with respect to the concentration of the entering ligand is illustrated in Figures 7 and 8 for the reaction of $\mathbf{1}^{+}$with $\mathrm{F}^{-}$and $\mathrm{NCS}^{-}$. Whereas the data for the thiocyanate reaction can be satisfactorily fitted to a straight line (eq 4 with $a=0.16 \pm 0.01 \mathrm{M}^{-1} \mathrm{~s}^{-1}$ ), the reaction with fluoride shows saturation kinetics (eq 5 with $a=$ $(2.6 \pm 0.6) \times 10^{3} \mathrm{M}^{-1} \mathrm{~s}^{-1}$ and $\left.b=12 \pm 9 \mathrm{M}^{-1}\right)$. However, equation 4 can be considered to be a simplification of eq 5 . The effect of the leaving ligand on the kinetics of reaction was checked by studying the reaction of $\mathbf{1}^{+}$with fluoride or thiocyanate in the presence of bromide. As shown in Figures 7 and 8, in no case there is the deceleration expected for a dissociative mechanism. The results are in both cases quite close to those obtained in the absence of bromide, and actually the values of $a$ and $b$ above have been obtained by fitting together the data in the absence and in the presence of leaving ligand. For the reaction with fluoride, the reaction is even somewhat faster in the presence of added bromide; although these differences could be associated to competition between both anions to form the different productive and unproductive outer-sphere complexes commented below, the kinetic differences are not large and this hinders a detailed analysis. In any case, these results clearly rule out a dissociative mechanism in which the leaving ligand dissociates before the entering ligand approaches the metal center. 


$$
k_{o b s}=a\left[N C S^{-}\right]
$$

$$
k_{\text {obs }}=\frac{a\left[F^{-}\right]}{1+b\left[F^{-}\right]}
$$

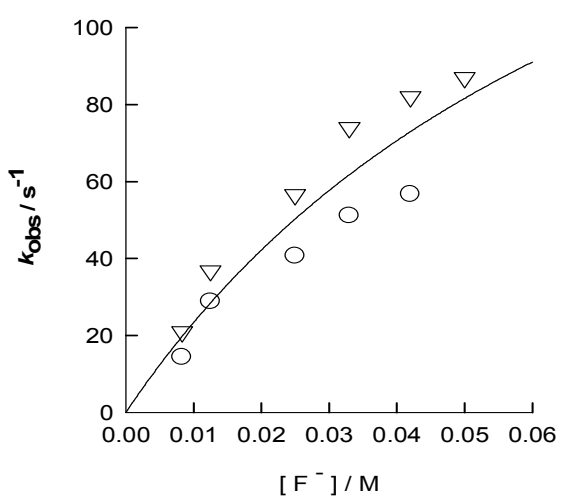

Figure 7. Plot showing the $\left[\mathrm{F}^{-}\right]$dependence of the observed rate constant for the reaction of $\mathbf{1}^{+}$with $\mathrm{F}^{-}$to form $3^{+}$. Triangles down correspond to reaction with added $\mathrm{Br}^{-}$and circles to no added $\mathrm{Br}^{-}$. In experiments with added $\mathrm{Br}^{-}$, the sum of the concentrations of both anions is $0.05 \mathrm{M}$. The solid line corresponds to the fit of all the data using equation 5.

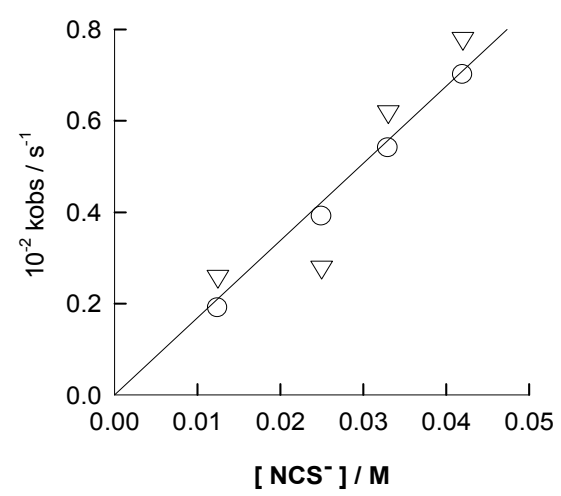

Figure 8. Plot showing the $\left[\mathrm{NCS}^{-}\right]$dependence of the observed rate constant for the reaction of $\mathbf{1}^{+}$ with $\mathrm{NCS}^{-}$to form $4^{+}$. Triangles down correspond to reaction with added $\mathrm{Br}^{-}$and circles to no added $\mathrm{Br}^{-}$. In experiments with added $\mathrm{Br}^{-}$, the sum of the concentrations of both anions is $0.05 \mathrm{M}$. The solid line corresponds to the fit of data using equation 4 . 
The kinetic data for substitution of coordinated bromide reveal that changing the nature of the entering ligand leads to a variety of rate laws and to changes of several orders of magnitude in the numerical values of the rate constants. These findings can be explained with the mechanism depicted in eqs $6-8$, in which there is a rapid preequilibrium that leads to formation of an outersphere complex between the cluster and the entering ligand, which is followed by rate-determining ligand exchange.

$$
\begin{array}{ll}
\mathbf{B r}-\mathbf{M}^{+}+\mathrm{Y}^{-} \rightleftarrows\left(\mathrm{Br}-\mathrm{M}^{+} \ldots \mathrm{Y}^{-}\right) & ; K_{\mathrm{os}} \\
\left(\mathbf{B r}-\mathbf{M}^{+} \ldots \mathrm{Y}^{-}\right) \rightarrow\left(\mathbf{Y}-\mathbf{M}^{+} \ldots \mathrm{Br}^{-}\right) & ; k_{2} \\
\left(\mathbf{Y}-\mathbf{M}^{+} \ldots \mathrm{Br}^{-}\right) \rightarrow \mathbf{Y}-\mathbf{M}^{+}+\mathrm{Br}^{-} & ; \text {fast }
\end{array}
$$

The rate law for this mechanism is given by eq (9), which has the same form that eq (5) with the equivalencies: $a=k_{2} K_{\mathrm{os}}$ and $b=K_{\mathrm{os}}$. Depending on the value of the $K_{\mathrm{os}}\left[\mathrm{Y}^{-}\right]$product, the rate law can be simplified to single first order dependence with respect to Y. From the experimental values of $a$ and $b$, it can be concluded that the kinetic differences observed for these substitutions can be associated to changes in any of the $k_{2}$ or $K_{\text {os }}$ terms.

$$
k_{o b s}=\frac{k_{2} K_{o s}\left[Y^{-}\right]}{1+K_{o s}\left[Y^{-}\right]}
$$

The reaction of clusters $\mathbf{2}^{+}$and $\mathbf{4}^{+}$with $\mathrm{F}^{-}$showed results quite close to those observed for the analogous reaction of $\mathbf{1}^{+}$, the values of $a$ and $b$ being now $a=(2.0 \pm 0.3) \times 10^{3} \mathrm{M}^{-1} \mathrm{~s}^{-1}$ and $b=33 \pm 8$ $\mathrm{M}^{-1}$ for substitution of $\mathrm{Cl}^{-}$and $a=(2.1 \pm 0.2) \times 10^{4} \mathrm{M}^{-1} \mathrm{~s}^{-1}$ and $b=180 \pm 12 \mathrm{M}^{-1}$ for substitution of $\mathrm{NCS}^{-}$. On the other hand, the reaction of $\mathbf{2}^{+}$with $\mathrm{NCS}^{-}$showed very small spectral changes (see Supporting Information), their magnitude increasing slightly when the concentration of $\mathrm{NCS}^{-}$is increased. As a consequence of these small changes, the dependence of the observed rate constants with respect to the concentration of thiocyanate is not clear, although they can be considered to be 
independent of the NCS concentration with a value of $k_{\mathrm{obs}}=0.040 \pm 0.007 \mathrm{~s}^{-1}$. These results suggest that the reaction occurs under conditions of reversibility, which is further supported by experiments with added $\mathrm{Cl}^{-}$, which indicated that the presence of the leaving ligand inhibits the reaction. In that case the values of $k_{\mathrm{obs}}$ would include contributions of the rates on both directions and the dependence with respect to the concentration of leaving and entering ligands would not be well defined because of the small changes. Quite similar conclusions were obtained when studying the kinetics of the reaction in the reverse direction, i.e. substitution of thiocyanate by chloride. In that case there is no reaction upon addition of the leaving ligand $\left(\mathrm{NCS}^{-}\right)$but reaction is observed when $\mathrm{Cl}^{-}$is the only anion added to the reaction medium. Nevertheless, the small amplitude of the absorbance changes hinders again a satisfactory kinetic analysis. When taken together with the rest of the observations in the present paper, it can be concluded that the stability of the complexes follows the order $\mathbf{1}^{+}<\mathbf{2}^{+} \approx \mathbf{4}^{+}<\mathbf{3}^{+}$, i.e. the maximum stability is achieved with the $\mathrm{F}^{-}$ligand which is not substituted by an excess of any of the other ligands, and the less stable is the $\mathrm{Br}^{-}$complex, which is easily substituted by all the other anions. The chloride and $\mathrm{NCS}^{-}$complexes are placed intermediate between the other two halides and their stabilities are close to each other.

From the kinetic point of view, the most striking observation is the rapidity of the reaction and the wide range of values observed for the rate constants, which span over several orders of magnitude. The dependence of the rate with the concentration of entering ligand and the lack of dependence with the concentration of leaving ligand can be interpreted by considering that substitutions have an associative character. Actually, we have recently found that ligand substitutions in this kind of cluster can go also through a particular associative mechanism in which the excess of electron density caused by attack by the entering ligand is compensated by reorganization of the cluster core, without dissociation of the leaving ligand (see Figure 9). ${ }^{4,17}$ The entering Y ligand coordinates to the metal centre without dissociation of the leaving $\mathrm{X}$, the process being accompanied of structural changes in the cluster core. 


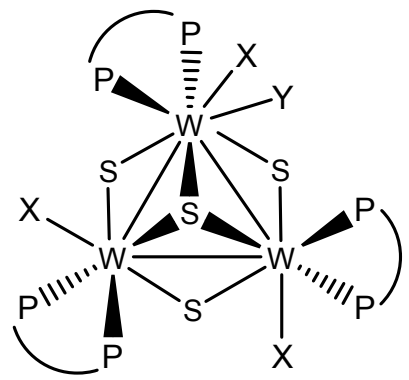

Figure 9. Proposed structure for the intermediate formed in associative substitution of $\mathrm{X}$ by $\mathrm{Y}$ in $\mathrm{M}_{3} \mathrm{~S}_{4}$ clusters.

\section{DFT calculations}

To gain insight into the intimate mechanism of these substitution reactions, DFT calculations were carried out using cluster $\mathbf{1}^{+}$as a starting model. The geometry of the cluster optimized at the B3LYP/lanl2dz level (see Supporting Information) compares well with that resolved by X-ray diffraction, the differences ranging in general from $1.2 \%$ to $5 \%$. The study of the substitution processes has been carried out at a single metal center, an approach that has been successfully employed in other theoretical studies ${ }^{6,16,17}$. We use the prime symbol to designate the compounds resulting from this single-center substitution. For instance, $\mathbf{2}^{+}$, refers to the cluster resulting from the substitution of one of the bromide ligands of $\mathbf{1}^{+}$by a chloride ligand, i. e., the $\left[\mathrm{W}_{3} \mathrm{~S}_{4} \mathrm{Br}_{2} \mathrm{Cl}(\mathrm{edpp})_{3}\right]^{+}$ cluster.

The energy values calculated in acetonitrile solution for the different substitutions starting from cluster $\mathbf{1}^{+}$are included in Table 4 , and they compare very well with the experimental results: the most stable compound is the fluoride complex while the less stable is the bromide adduct. Clusters containing $\mathrm{Cl}^{-}$and $\mathrm{NCS}^{-}$are close in energy.

Table 4. Summary of the energies $(\Delta \mathrm{E}, \mathrm{kcal} / \mathrm{mol})$ and Gibbs free energies $(\Delta \mathrm{G}, \mathrm{kcal} / \mathrm{mol})$ calculated in acetonitrile solution for the different substitution reactions in cluster $\mathbf{1}^{+}$.

\begin{tabular}{l|cc}
\hline Reaction & $\Delta \mathrm{E} \quad \Delta \mathrm{G}$ \\
\hline
\end{tabular}




\begin{tabular}{l|cc}
\hline $\mathbf{1}^{+}+\mathrm{Cl}^{-} \rightleftharpoons \mathbf{2}^{+\boldsymbol{9}}+\mathrm{Br}^{-}$ & -11.2 & -9.3 \\
$\mathbf{1}^{+}+\mathrm{F}^{-} \rightleftharpoons \mathbf{3}^{+},+\mathrm{Br}^{-}$ & -48.1 & -45.5 \\
$\mathbf{1}^{+}+\mathrm{NCS}^{-} \rightleftharpoons \mathbf{4}^{+},+\mathrm{Br}^{-}$ & -15.2 & -9.8 \\
\hline
\end{tabular}

The next step was to construct potential energy surfaces (PES) for the substitution of one of the bromides by the different $\mathrm{Y}^{-}$entering ligands: $\mathrm{Cl}^{-}, \mathrm{F}^{-}$and $\mathrm{NCS}^{-}$. As kinetic data rule out a limiting dissociative mechanism in which $\mathrm{Br}^{-}$leaves the coordination site before approach of the entering ligand, $\left(\mathbf{1}^{+}, \mathrm{Y}^{-}\right)$adducts with $\mathrm{Y}^{-}$approaching to one of the $\mathrm{W}$ centers at the proximities of the $\mathrm{W}-\mathrm{Br}$ bond were used as starting point for modelling the potential energy surface corresponding to the substitution process. This approach is also based on the NMR observations indicating that the entering ligand approaches the metal center in the same direction than the leaving ligand. The final point in those calculations was the adduct that results from $\mathrm{Br}^{-}$release from $\mathbf{1}^{+}$to afford $\mathbf{2}^{+}, \mathbf{3}^{+}$, or $4^{+}$. The calculated surfaces are shown in Figure 10 and indicate a rich mechanistic chemistry for these substitutions.

In the case of fluoride as entering ligand (Figure 10a), an associative interchange of the ligands is predicted for the bromide substitution: the minimum energy path (MEP) from the left (reactants) to the right (products) corners of the PES begins with a shortening of the W-F distance without concomitant enlarging of the $\mathrm{W}-\mathrm{Br}$ distance. The point of maximum energy of the MEP shows W-F and W-Br distances of 2.82 and $2.92 \AA$ respectively, and it was used as the starting point for calculating the corresponding transition state (TS), whose geometry is depicted in Figure 11a. The W-F distance is now $2.92 \AA$, slightly longer than the one predicted from the PES, and the W-Br distance is only $2.77 \AA$ at the TS, which is essentially the same than the W-Br distances in the other two metallic centers (2.75 and $2.77 \AA$ ). Hence, the associative character of the ligand exchange is confirmed and even strengthened when the true TS is found. The geometry of the TS shows that the bond distances between $\mathrm{W}$ and both the capping $\mathrm{S}$ and the bridging $\mathrm{S}$ trans to the $\mathrm{NH}_{2}$ group essentially remain unchanged upon addition of the fluoride, while the $\mathrm{W}-(\mu-\mathrm{S})$ distance trans to the 
leaving $\mathrm{Br}$ increases from 2.36-2.38 $\AA$ to $2.48 \AA$. Thus, it appears that the excess of electron density introduced by the entering ligand is accommodated by weakening the trans W-S bond. Intrinsic reaction coordinate (IRC) calculations from the TS led to adducts whose optimized structures are shown in Figure 12. Those structures indicate the formation of outer sphere complexes between the cluster and the anion, in agreement with previous reports on related systems. ${ }^{56}$ The stability of the different outer-sphere complexes can be estimated from the relative energy values, listed in Table 5, with regard to those of the separated ions. In general, free energies are close to zero, except for the $\left(\mathbf{1}^{+}, \mathrm{F}^{-}\right)$adduct (see Figure 12), which is significantly more stable than the other outer-sphere complexes. A detailed inspection of the geometry reveals that $\mathrm{F}^{-}$approaches the cluster at the proximities of the amino group of the edpp ligand coordinated to the adjacent $\mathrm{W}$, in such a way that there is a strong interaction with one of the $\mathrm{H}$ atoms $(\mathrm{H} \cdots \mathrm{F}$ distance of $1.02 \AA)$, that is almost extracted from the edpp ligand. In the other outer-sphere complex, $\left(3^{+}, \mathrm{Br}^{-}\right)$, the anion also interacts with one hydrogen of an amino group but the interaction is much weaker $(\mathrm{H} \cdots \mathrm{Br}$ distance of c.a. 2 $\AA$ ). The importance of the $\mathrm{H} \cdots \mathrm{F}$ interaction is also evident in the corresponding transition state (Figure 11a), which shows an $\mathrm{H}^{\cdots} \mathrm{F}$ distance of $1.37 \AA$ that clearly suggests that the entering of fluoride is assisted by the hydrogen atom of the amino moiety of the vicinal edpp.

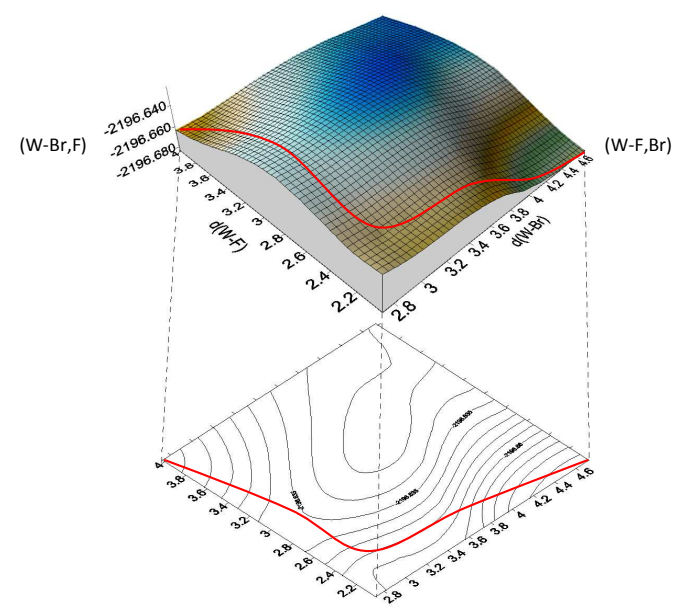

(a) 
Figure 10. Potential Energy Surfaces for the substitution of one of the $\mathrm{Br}^{-}$of $\mathbf{1}^{+}$by the different entering ligands $\mathrm{Y}^{-}$. The absolute energy (hartrees/particle) is depicted as a function of the W-Br and W-Y distances $(\AA)$. (a), $\mathrm{Y}^{-}=\mathrm{F}^{-} ;(\mathrm{b}), \mathrm{Y}^{-}=\mathrm{Cl}^{-} ;(\mathrm{c}), \mathrm{Y}^{-}=\mathrm{NCS}^{-}$. The surfaces have been depicted in such a way that $\mathbf{1}^{+}$plus $\mathrm{Y}^{-}$is always located on the left corner, while $\mathbf{3}^{+}, \mathbf{2}^{+}$, or $\mathbf{4}^{+}$( $(\mathrm{a}, \mathrm{b}$ and c, respectively) plus $\mathrm{Br}^{-}$are always located on the right corners, as indicated. The minimum energy paths have been sketched (red lines, associative pathways; blue lines, dissociative pathways). 


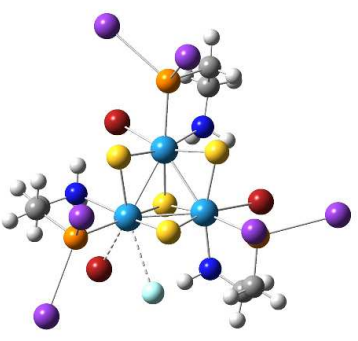

(a)

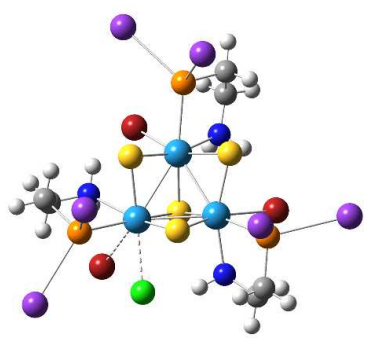

(b)

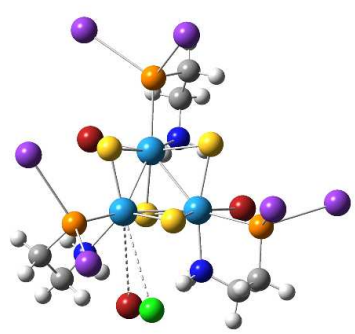

(c)

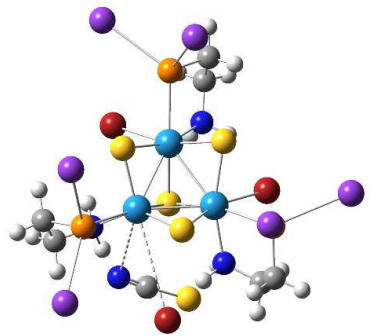

(d)

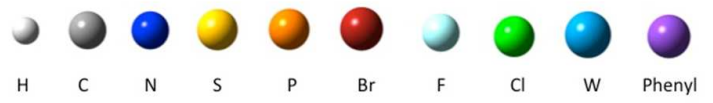

Figure 11. The transitions states found for substitution of coordinated bromide in $\mathbf{1}^{+}$: (a) TS for the bromide exchange by fluoride; (b) TS for the associative interchange pathway for the bromide exchange by chloride; (c) TS for the dissociative interchange pathway for the bromide exchange by chloride; and (d) TS for the bromide exchange by thiocyanate. The dashed lines connect the leaving $\mathrm{Br}$ and the entering ligand with the metal center. The phenyl groups of the edpp ligands have been substituted by violet spheres for clarity.
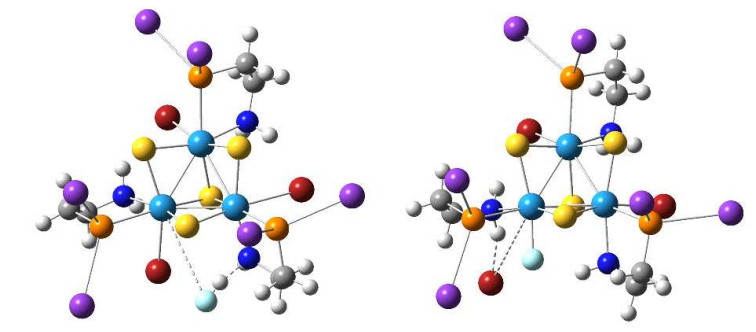

$\left(1^{+}, \mathrm{F}\right)$

$\left(3^{+}, \mathrm{Br}\right)$ 
Figure 12. Optimized geometries for outer-sphere complexes formed by clusters $\mathbf{1}^{+}$and $\mathbf{3}^{+}$with the anions: $\left(\mathbf{1}^{+}, \mathrm{F}^{-}\right)$and $\left(3^{+}, \mathrm{Br}^{-}\right)$represent the outer-sphere complexes participating in the substitution of $\mathrm{Br}^{-}$by $\mathrm{F}^{-}$through the corresponding pathway in Figure 10a. The dashed lines indicate short contacts and/or long-range interactions. Outer-sphere complexes with subscripts B or C correspond to alternative structures unproductive for substitution. The phenyl groups of the edpp ligands have also been omitted for clarity.

The energies in Table 5 anticipate that in solution the equilibrium between the free cluster and the outer-sphere complex, would be displaced towards the latter species when the entering ligand is $\mathrm{F}^{-}$but to the free cluster for other ligands. However, it must be noted that the outer-sphere complexes commented above correspond to $\mathrm{Y}^{-}$approaching the $\mathrm{W}$ center in a particular orientation that favors the substitution process, but other orientations are also possible for the entering anions, as experimentally found for related systems. ${ }^{56}$ As outer-sphere complexes with these alternative structures are usually unable to evolve to the substitution product, they would represent dead-end species that would simply compete with productive outer-sphere complexes and make reaction to slow down. Although the formation of these alternative outer-sphere complexes has not been 
explored in detail, several possibilities have been analyzed as shown in Figure 12. Structures $\left(\mathbf{1}^{+}, \mathrm{F}^{-}\right.$ )$_{\mathrm{B}}$ and $\left(3^{+}, \mathrm{Br}^{-}\right)_{\mathrm{B}}$ were obtained by approaching the uncoordinated anion to the cluster at the proximities of the three $\mathrm{NH}_{2}$ groups, and again the strong interaction of fluoride with one of the $\mathrm{H}$ atoms is revealed in the $\left(\mathbf{1}^{+}, \mathrm{F}^{-}\right)_{\mathrm{B}}$ case. Structures $\left(\mathbf{1}^{+}, \mathrm{F}^{-}\right)_{\mathrm{C}}$ and $\left(\mathbf{3}^{+}, \mathrm{Br}^{-}\right)_{\mathrm{C}}$ were obtained by approaching the anion at the proximities of the three bridging sulfurs, being the outer-sphere complex less stable in this case. The energy values (see Table 5) for various productive and unproductive outer-sphere complexes are similar in most cases.

Table 5 also includes the values of $\Delta \mathrm{E}^{\#}$ and $\Delta \mathrm{G}^{\#}$ calculated in acetonitrile solution for the different substitutions. In all cases the values are expressed with respect to the corresponding outersphere complex formed between the starting cluster and the entering ligand. The activation barrier calculated for substitution of $\mathrm{Br}^{-}$by $\mathrm{F}^{-}$by internal associative attack within the outer-sphere complex is moderate, and all stationary points in the reaction profile lie below the energy of starting reactants (see Supporting information) in agreement with the experimental observation of a rapid reaction. As the $b$ term in equation 5 can be related to the stability of the outer sphere complex, the high stability calculated for the case of entering fluoride is also in agreement with the experimental observation of the rate law in equation 5 for substitutions with this entering anion; in contrast, the values of $b$ for other anions would be smaller and the rate law would be simplified to equation 4 .

Table 5. Summary of the energies $(\Delta \mathrm{E}, \mathrm{kcal} / \mathrm{mol})$ and Gibbs free energies $(\Delta \mathrm{G}, \mathrm{kcal} / \mathrm{mol})$ calculated in acetonitrile solution for the formation of outer-sphere complexes, and activation parameters calculated for the different substitution reactions in cluster $\mathbf{1}^{+}$. Outer-sphere complexes without subscript are those involved in substitution, whereas those labelled B and C correspond to alternative structures unproductive in the substitution reaction.

\begin{tabular}{c|cccc}
\hline $\begin{array}{c}\text { Outer-sphere } \\
\text { complex }\end{array}$ & $\Delta \mathrm{E}^{\mathrm{a}}$ & $\Delta \mathrm{G}^{\mathrm{a}}$ & $\Delta \mathrm{E}^{\# \mathrm{~b}}$ & $\Delta \mathrm{G}^{\# \mathrm{~b}}$ \\
\hline$\left(\mathbf{1}^{+}, \mathrm{Cl}^{-}\right)$ & -8.8 & 2.2 & $17.1^{\mathrm{c}}$ & $16.5^{\mathrm{c}}$ \\
$\left(\mathbf{1}^{+}, \mathrm{F}^{-}\right)$ & -27.4 & -21.4 & 16.9 & 21.3 \\
\hline
\end{tabular}


${ }^{a}$ Relative to separated ions. ${ }^{\mathrm{b}}$ Relative to the corresponding outer-sphere complex. ${ }^{\mathrm{c}}$ These values correspond to the dissociative interchange pathway. The values for the associative interchange pathway are $\Delta E^{\#}=30.3 \mathrm{kcal} / \mathrm{mol}$ and $\Delta \mathrm{G}^{\#}=28.7 \mathrm{kcal} / \mathrm{mol}$. In the gas phase the energy differences between both pathways are smaller: $\Delta \mathrm{E}^{\#}=27.0 \mathrm{kcal} / \mathrm{mol}$ and $\Delta \mathrm{G}^{\#}=26.0 \mathrm{kcal} / \mathrm{mol}$ for the dissociative interchange, and $\Delta E^{\#}=24.3 \mathrm{kcal} / \mathrm{mol}$ and $\Delta \mathrm{G}^{\#}=25.9 \mathrm{kcal} / \mathrm{mol}$ for the associative interchange.

In the case of chloride as entering ligand, the PES (Figure 10b) reveals two possible pathways with close energy barriers. One of them corresponds to an associative interchange analogous to that described for fluoride as entering ligand, and the TS (Figure 11b) calculated from the geometry at the maximum energy point in this pathway shows $\mathrm{W}-\mathrm{Br}$ and $\mathrm{W}-\mathrm{Cl}$ distances of 3.38 and $2.65 \AA$, respectively. Although the $\mathrm{W}$-Br distance is now longer, the associative character of the pathway is maintained. In this case the entering of the chloride is not as clearly assisted as in the preceding case by one of the hydrogen atoms of the amino group of the vicinal edpp ligand, the $\mathrm{H}-\mathrm{Cl}$ distance being now of $2.10 \AA$. The other pathway in the PES of Figure $10 \mathrm{~b}$ corresponds to a dissociative interchange, the transition state (Figure 11c) showing now $\mathrm{W}-\mathrm{Br}$ and $\mathrm{W}-\mathrm{Cl}$ distances of 4.51 and $3.81 \AA$, respectively. Both distances are much larger than those in the TS for the other pathway, so that a partially vacant coordination site can be considered to be generated, the process being accompanied by minor changes in the remaining bond distances. The activation barriers calculated in the gas phase for the two pathways are very close to each other, which suggest that reaction can go through both parallel pathways. However, significant differences are found when the 
acetonitrile solvent is included in the calculations since the dissociative interchange turns out to be clearly preferred. This can be justified by taking into account that this mechanism implies a greater charge separation than the associative interchange. Thus, it appears that for the bromide-by-chloride exchange both mechanisms are feasible, but the polar acetonitrile solvent would favor the mechanism with greater charge separation. Unfortunately, the impossibility of obtaining kinetic data for this reaction hinders additional analysis.

For the reaction with thiocyanate (Figure 10c), calculations were made with the entering ligand coordinating to the metal center through the $\mathrm{N}$ atom, as experimentally found. In this case a single pathway is evident in the PES, and optimization of the corresponding transition state (Figure 11d) indicates $\mathrm{W}-\mathrm{Br}$ and $\mathrm{W}-\mathrm{N}$ distances of 4.08 and $3.86 \AA$, respectively. The TS Gibbs free energy is $19 \mathrm{kcal} / \mathrm{mol}$ higher than the starting reactants value (see Supporting Information), in agreement with the experimental observation of a slower reaction with thiocyanate compared with fluoride. The lower stability of the outer-sphere complex with entering thiocyanate is also in agreement with the observation of an experimental rate law with the form of equation 4.

As a summary, the results of DFT calculations agree well with the experimental observations, both for thermodynamic and kinetic aspects. Thus, the energy values in Table 4 agree with the reactivity behavior observed, justifying important observations as the lack of reactivity of the fluoride-containing cluster with other anions and the order of stability observed $\left(\mathbf{1}^{+}<\mathbf{2}^{+} \approx \mathbf{4}^{+}<\right.$ $\mathbf{3}^{+}$). With regard to the kinetics of reaction, the calculated reaction profiles are in all cases compatible with the experimental observation of reactions in the stopped-flow time scale, although with significantly different rate constants. Thus, the reaction of $\mathbf{1}^{+}$with $\mathrm{F}^{-}$is calculated to be faster than with $\mathrm{NCS}^{-}$, in agreement with the experiments. Moreover, the experimental rate laws correlate well with the stabilities calculated for the different outer-sphere complexes, so that reactions with fluoride occur with significant curvature of the kinetic plots (eq 5) while other reactions lack of this curvature.

\section{Conclusion}


In conclusion, new trinuclear incomplete cubane-type $\mathrm{W}_{3} \mathrm{~S}_{4}$ tungsten clusters bearing aminophosphine ligands have been synthesized for the first time by reacting easily available $\mathrm{W}_{3} \mathrm{~S}_{7}$ precursors with the corresponding ligand. Interestingly, only one of the possible isomers of $\left[\mathrm{W}_{3} \mathrm{~S}_{4} \mathrm{X}_{3}(\mathrm{edpp})_{3}\right]^{+}(\mathrm{X}=\mathrm{F}, \mathrm{Cl}, \mathrm{Br}, \mathrm{NCS})$ is formed in almost quantitative yields, and this geometry is maintained in substitution reactions of the ancillary $\mathrm{X}^{-}$ligands. In the structure, the nitrogen atoms of the amino group and the terminal halide atoms are located above the trimetallic plane and the phosphorous atoms are placed below it. These complexes extend the family of the phosphine cuboidal $\mathrm{W}_{3} \mathrm{~S}_{4}$ clusters by including an amino group that may have a definite role on catalytic processes.

Substitution of the ancillary $\mathrm{X}^{-}$ligand occurs readily when thermodynamically favoured, and the intermediates involved in the sequential reaction at the three metal centers have been identified by NMR and ESI-MS. However, stopped-flow experiments indicate that these processes occur in a single kinetic step, thus indicating that the kinetics is controlled by the statistics. In addition, the kinetic data reveal a variety of rate laws for the substitution processes depending on the nature of the starting cluster and the entering ligand, and the numerical values of the rate constants show differences of several orders of magnitude when varying the entering ligand. The whole set of data can be explained with a mechanism in which there is a rapid pre-equilibrium that leads to formation of an outer-sphere complex followed by rate-determining ligand exchange, in a process that can show a variety of behaviors according to the results of DFT calculations. The theoretical work herein reported, including the solvent effects, nicely explains the experimental observations.

Although the limited kinetic data available hinders a detailed analysis, it appears evident at this time that $\mathrm{F}^{-}$as entering ligand leads to very stable outer-sphere complexes (larger $K_{\mathrm{os}}$ ) because of the interaction with the vicinal amino group, and this interaction assists the substitution process making it to go faster. However, as the calculations also justify the formation of unproductive outersphere complexes with the entering ligand approaching to the cluster far from the entering ligand, 
there is the possibility of an additional $\mathrm{K}_{\text {os }}{ }\left[\mathrm{Y}^{-}\right]$term in the denominator that would contribute to changes in the experimental values of $b$, thus adding difficulties to the analysis.

In any case, the experimental and theoretical studies described in the present paper provide a detailed kinetico-mechanistic description of substitutions of these clusters in non-aqueous media. Whereas the lack of protic equilibria simplifies the reaction mechanism with respect to those observed for water substitution by avoiding reaction pathways involving conjugated bases, the mechanistic behavior can be still quite rich because of the possibility of different reaction pathways that differ in the associative-dissociative character of the ligand interchange.

\section{Supporting Information}

CIF and listings of spectroscopic, spectrometric, and kinetic data for $\mathbf{1}^{+}$to $\mathbf{4}^{+}$complex salts. DFT computed energy profiles, cartesian coordinates, electronic and Gibbs free energies for the optimized structures, as well as imaginary frequencies for transition state structures, are reported. This material is available free of charge via the Internet at http://pubs.acs.org.

\section{Acknowledgments}

The financial support of the Spanish Ministerio de Economía y Competitividad and FEDER program of the E. U. (Grants CTQ2011-23157, CTQ2012-36253-C03-02 and CTQ2012-37821-C02-02), Universitat Jaume I (Research Project P1·1B2013-19, P1·1B2013-40), Junta de Andalucía (Grupo FQM-137) and Generalitat Valenciana (ACOMP/2013/215 and Prometeo/2014/022) is gratefully acknowledged. The authors also thank the Servei Central d'Instrumentació Científica (SCIC) of the University Jaume I for providing us with the mass spectrometry, NMR and X-ray facilities. T. B. thanks the Spanish Ministerio de Ciencia e Innovación (MICINN) for a doctoral fellowship (FPI). J.A.P.C. also acknowledges a grant from Junta de Andalucía.

\section{References}


(1) Zhao, B.; Han, Z.; Ding, K. Angew. Chem. Int. Ed. 2013, 52, 4744.

(2) Seino, H.; Hidai, M. Chem. Sci. 2011, 2, 847.

(3) Guillamon, E.; Llusar, R.; Perez-Prieto, J.; Stiriba, S.-E. J. Organomet. Chem. 2008, 693, 1723.

(4) Algarra, A. G.; Feliz, M.; Fernández-Trujillo, M. J.; Llusar, R.; Safont, V. S.; Vicent, C.; Basallote, M. G. Chem. Eur. J. 2009, 15, 4582.

(5) Algarra, A. G.; Basallote, M. G.; Fernandez-Trujillo, M. J.; Feliz, M.; Guillamon, E.; Llusar, R.; Sorribes, I.; Vicent, C. Inorg. Chem. 2010, 49, 5935.

(6) Beltran, T. F.; Feliz, M.; Llusar, R.; Mata, J. A.; Safont, V. S. Organometallics 2011, 30, 290.

(7) Beltran, T. F.; Feliz, M.; Llusar, R.; Safont, V. S.; Vicent, C. Catal. Today 2011, 177, 72.

(8) Basallote, M. G.; Jesus Fernandez-Trujillo, M.; Angel Pino-Charnorro, J.; Beltran, T. F.; Corao, C.; Llusar, R.; Sokolov, M.; Vicent, C. Inorg. Chem. 2012, 51, 6794.

(9) Sorribes, I.; Wienhoefer, G.; Vicent, C.; Junge, K.; Llusar, R.; Beller, M. Angew. Chem. Int. Ed. 2012, 51, 7794 .

(10) Beltran, T. F.; Feliz, M.; Llusar, R.; Safont, V. S.; Vicent, C. Eur. J. Inorg. Chem. 2013, 2013, 5797.

(11) Beltran, T. F.; Llusar, R.; Sokolov, M.; Basallote, M. G.; Jesus Fernandez-Trujillo, M.; Angel Pino-Chamorro, J. Inorg. Chem. 2013, 52, 8713.

(12) Guiry, P. J.; Saunders, C. P. Adv. Synth. Catal. 2004, 346, 497.

(13) Gopalakrishnan, J. Appl. Organomet. Chem. 2009, 23, 291.

(14) Stepanova, V. A.; Smoliakova, I. P. Curr. Org. Chem. 2012, 16, 2893.

(15) Algarra, A. G.; Basallote, M. G.; Feliz, M.; Fernandez-Trujillo, M. J.; Guillamon, E.; Llusar, R.; Vicent, C. Inorg. Chem. 2006, 45, 5576.

(16) Algarra, A. G.; Basallote, M. G.; Feliz, M.; Fernandez-Trujillo, M. J.; Llusar, R.; Safont, V. S. Chem. Eur. J. 2006, 12, 1413. 
(17) Algarra, A. G.; Basallote, M. G.; Feliz, M.; Jesus Fernandez-Trujillo, M.; Llusar, R.; Safont, V. S. Chem. Eur. J. 2010, 16, 1613.

(18) Jia, W.; Chen, X.; Guo, R.; Sui-Seng, C.; Amoroso, D.; Lough, A. J.; Abdur-Rashid, K. Dalton Trans. 2009, 8301.

(19) Hounjel, L. J.; Bierenstiel, M.; Ferguson, M. J.; McDonald, R.; Cowie, M. Inorg. Chem. 2010, 49, 4288.

(20) Xie, J.-B.; Xie, J.-H.; Liu, X.-Y.; Kong, W.-L.; Li, S.; Zhou, Q.-L. J. Am. Chem. Soc. 2010, 132,4538 .

(21) Xie, J.-B.; Xie, J.-H.; Liu, X.-Y.; Zhang, Q.-Q.; Zhou, Q.-L. Chem. Asian J. 2011, 6, 899.

(22) Xie, J.-H.; Liu, X.-Y.; Yang, X.-H.; Xie, J.-B.; Wang, L.-X.; Zhou, Q.-L. Angew. Chem. Int. Ed. 2012, 51, 201.

(23) Zhu, S.-F.; Yu, Y.-B.; Li, S.; Wang, L.-X.; Zhou, Q.-L. Angew. Chem. Int. Ed. 2012, 51, 8872.

(24) Fuentes, J. A.; Carpenter, I.; Kann, N.; Clarke, M. L. Chem. Commun. 2013, 49, 10245.

(25) Kayan, C.; Meric, N.; Aydemir, M.; Ocak, Y. S.; Baysal, A.; Temel, H. Appl. Organomet. Chem. 2014, 28, 127.

(26) Rafikova, K.; Kystaubayeva, N.; Aydemir, M.; Kayan, C.; Ocak, Y. S.; Temel, H.; Zazybin, A.; Gurbuz, N.; Ozdemir, I. J. Organomet. Chem. 2014, 758, 1.

(27) Estevan, F.; Feliz, M.; Llusar, R.; Mata, J. A.; Uriel, S. Polyhedron 2001, 20, 527.

(28) Feliz, M.; Guillamon, E.; Llusar, R.; Vicent, C.; Stiriba, S. E.; Perez-Prieto, J.; Barberis, M. Chem. Eur. J. 2006, 12, 1486.

(29) Llusar, R.; Vicent, C. in Inorganic Chemistry In Focus III ed. G. Meyer, D. Naumann, L. Wesermann; WILEY-VCH, Weinheim (Germany) 2006.

(30) Algarra, A. G.; Basallote, M. G.; Fernandez-Trujillo, M. J.; Guillamon, E.; Llusar, R.; Segarra, M. D.; Vicent, C. Inorg. Chem. 2007, 46, 7668.

(31) Ooi, B. L.; Sykes, A. G. Inorg. Chem. 1988, 27, 310.

(32) Ooi, B. L.; Sykes, A. G. Inorg. Chem. 1989, 28, 3799. 
(33) Hernandez-Molina, R.; Sykes, A. G. Coord. Chem. Rev. 1999, 187, 291.

(34) Hernandez-Molina, R.; Sykes, A. G. J. Chem. Soc., Dalton Trans. 1999, 3137.

(35) Hernandez-Molina, R.; Sokolov, M. N.; Sykes, A. G. Acc. Chem. Res. 2001, 34, 223.

(36) MASSLYNX, 4.0 ed. (Ed.: W. Itd), 2005.

(37) Fedin, V. P.; Sokolov, M. N.; Gerasko, O. A.; Kolesov, B. A.; Fedorov, V. Y.; Mironov, A. V.; Yufit, D. S.; Slovohotov, Y. L.; Struchkov, Y. T. Inorg. Chim. Acta 1990, 175, 217.

(38) CrysAlisPro version 171.36.24; Agilent Technologies, Santa Clara, CA, 2012.

(39) Clark, R. C.; Reid, J. S. Acta Crystallogr., Sect. A 1995, 51, 887.

(40) Sheldrick, G. M. Acta Crystallogr., Sect. A 2008, 64, 112.

(41) Dolomanov, O. V.; Bourhis, L. J.; Gildea, R. J.; Howard, J. A. K.; Puschmann, H. J. Appl. Crystallogr. 2009, 42, 339.

(42) Crystal Impact Diamond-Crystal and Molecular Structure Visualization (2008) Crystal Impact-Brandenburg K and Putz H GbR, Postfach 1251, D-53002 Bonn.

(43) Binstead, R. A.; Jung, B.; Zuberbühler, A. D.; Spectrum Software Associates: Chappel Hill, 2000.

(44) Lee, C. T.; Yang, W. T.; Parr, R. G. Phys. Rev. B 1988, 37, 785.

(45) Frisch, M. J.; Trucks, G. W.; Schlegel, H. B.; Scuseria, G. E.; Robb, M. A.; Cheeseman, J. R.; Scalmani, G.; Barone, V.; Mennucci, B.; Petersson, G. A.; Nakatsuji, H.; Caricato, M.; Li, X.; Hratchian, H. P.; Izmaylov, A. F.; Bloino, J.; Zheng, G.; Sonnenberg, J. L.; Hada, M.; Ehara, M.; Toyota, K.; Fukuda, R.; Hasegawa, J.; Ishida, M.; Nakajima, T.; Honda, Y.; Kitao, O.; Nakai, H.; Vreven, T.; Montgomery, J. A., Jr.; Peralta, J. E.; Ogliaro, F.; Bearpark, M.; Heyd, J. J.; Brothers, E.; Kudin, K. N.; Staroverov, V. N.; Kobayashi, R.; Normand, J.; Raghavachari, K.; Rendell, A.; Burant, J. C.; Iyengar, S. S.; Tomasi, J.; Cossi, M.; Rega, N.; Millam, N. J.; Klene, M.; Knox, J. E.; Cross, J. B.; Bakken, V.; Adamo, C.; Jaramillo, J.; Gomperts, R.; Stratmann, R. E.; Yazyev, O.; Austin, A. J.; Cammi, R.; Pomelli, C.; Ochterski, J. W.; Martin, R. L.; Morokuma, K.; Zakrzewski, V. G.; Voth, G. A.; Salvador, 
P.; Dannenberg, J. J.; Dapprich, S.; Daniels, A. D.; Farkas, Ö.; Foresman, J. B.; Ortiz, J. V.;

Cioslowski, J.; Fox, D. J.; Revision B.01 ed.; Gaussian Inc.: Wallingford CT, 2010.

(46) Feliz, M.; Llusar, R.; Andres, J.; Berski, S.; Silvi, B. New J. Chem. 2002, 26, 844.

(47) Vicent, C.; Feliz, M.; Llusar, R. J. Phys. Chem. A 2008, 112, 12550.

(48) Fukui, K. Acc. Chem. Res. 1981, 14, 363.

(49) Miertus, S.; Scrocco, E.; Tomasi, J. Chem. Phys. 1981, 55, 117.

(50) Pascualahuir, J. L.; Silla, E.; Tunon, I. J. Comput. Chem. 1994, 15, 1127.

(51) Cotton, F. A.; Llusar, R. Polyhedron 1987, 6, 1741.

(52) Sasaki, M.; Sakane, G.; Ouchi, T.; Shibahara, T. J. Cluster Sci. 1998, 9, 25.

(53) Beltran, T. F. Clústeres Sulfuro Trimetálicos de Molibdeno y Wolframio Funcionalizados con Ligandos Difosfina o Aminofosfina y sus Aplicaciones en Catálisis Orgánica (ISBN 97884-697-1305-1), Ph. D. Thesis, Universitat Jaume I, September 2013.

(54) Ball, N. D.; Kampf, J. W.; Sanford, M. S. Dalton Trans. 2010, 39, 632.

(55) Algarra, A. G.; Jesus Fernandez-Trujillo, M.; Basallote, M. G. Chem. Eur. J. 2012, 18, 5036.

(56) Algarra, A. S. G.; Basallote, M. G.; Jesus Fernandez-Trujillo, M.; Llusar, R.; Safont, V. S.; Vicent, C. Inorg. Chem. 2006, 45, 5774. 


\title{
For Table of Contents Only
}

1

2

3

4

5

6

7

8

9

10

11

12

13

14

15

16

17

18

19

20

21

22

23

24

25

26

27

28

29

30

31

32

33

34

35

36

37

38

39

40

41

42

43

44

45

46

47

48

49

50

51

52

53

54

55

56

57

58

59

60

\begin{abstract}
An aminophosphine ligand has been coordinated to the $\mathrm{W}_{3}\left(\mu_{3}-\mathrm{S}\right)(\mu-\mathrm{S})_{3}$ cluster, the resulting compound undergoing easy substitution of the ancillary Br ligand; ESI-MS, NMR, stopped-flow and DFT information indicate an interchange substitution strongly dependent on the nature of the entering ligand.
\end{abstract}

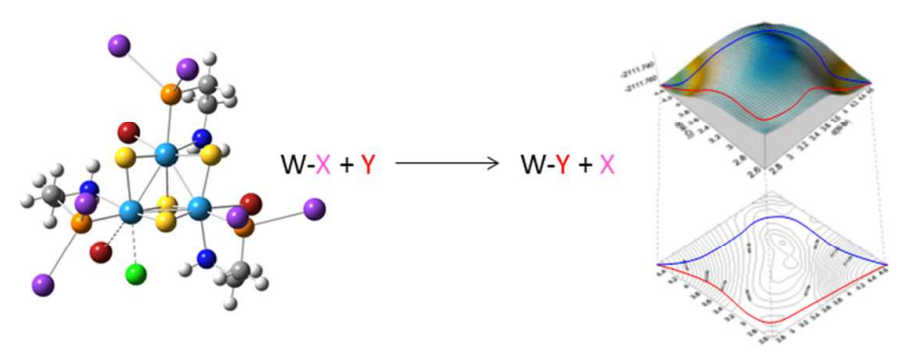

